Research Article

\title{
Stress Distribution and Optimum Spacing Determination of Double-Withdrawal-Channel Surrounding Rocks: A Case Study of Chinese Coal Mine
}

\author{
Yanjun $\mathrm{He} \mathbb{D}^{1,2}$ and Jianhua $\mathrm{Li}^{2}$ \\ ${ }^{1}$ Institute of Mining Engineering, Inner Mongolia University of Science and Technology, Baotou 014010, Inner Mongolia, China \\ ${ }^{2}$ Lijiahao Mine, Shenhua Baotou Energy Co., Ltd., Erdos 017000, Baotou, China \\ Correspondence should be addressed to Yanjun He; heyanjun1989@126.com
}

Received 16 March 2021; Accepted 16 June 2021; Published 5 July 2021

Academic Editor: Feng Du

Copyright (C) 2021 Yanjun He and Jianhua Li. This is an open access article distributed under the Creative Commons Attribution License, which permits unrestricted use, distribution, and reproduction in any medium, provided the original work is properly cited.

In this study, the 31113 fully mechanised working face in the Lijiahao Coal Mine was selected as the project background. The failure characteristics and optimum spacing of a double-withdrawal-channel surrounding rock were extensively investigated through field measurements, theoretical analysis, and numerical simulations. The following results were obtained. The loading influence range of the working face was fixed. Under the influence of mining, the stress distribution variation in the doublewithdrawal channels with spacing and the influence of stress distribution on the surrounding rock stability of the withdrawal channels were determined. The optimum distance between the double-withdrawal channels to achieve the stability of the surrounding rock was at least $25 \mathrm{~m}$, and engineering measures are required to limit the mining height in the final mining stage. The rationality of the main and auxiliary withdrawal channel spacing of $25 \mathrm{~m}$ and measures to limit the mining height in the final stage were demonstrated. The findings of this study provide a valuable reference for constructing the layout of withdrawal channels in the adjacent working faces of the same mining area.

\section{Introduction}

Withdrawal channels are unique roadways used for equipment withdrawal after the coal face has finished mining [1]. In mine production, a critical factor that influences the production efficiency of the working face is whether the working face equipment can be withdrawn smoothly [2]. While ensuring withdrawal, its speed becomes a crucial issue $[3,4]$.

The stability of the surrounding rock of the withdrawal channel is threatened, owing to the impact of mining on the working face $[5,6]$. Many scholars have investigated the stress distribution characteristics of dynamic pressure roadways and surrounding rock control [7-9]. Guo et al. analysed the dynamic failure characteristics of the surrounding underground rock and the failure evolution under different stresses and revealed the butterfly failure mechanism [10-12]. By combining a physical model and numerical simulations, Ghabraie et al. established the overlying rock migration law of an extended wall working face in single-coal and multicoal seam mining [13-15]. Through theoretical analysis, similar material simulation experiments, and numerical simulations, Yang et al. proposed a stress distribution law, determined the plastic failure range and reasonable coal pillar size near the working face, and achieved a good application effect $[16,17]$. Li et al. established a calculation model to examine the influence of three factors, i.e., the thickness and position of the interbedded coal seam and the width of the bifurcation roadway rock pillar, on the displacement, plastic zone, and asymmetric deformation of the critical points of the roadway. They also analysed the deformation and failure mechanism of the surrounding rock and proposed asymmetric joint control countermeasures [18-20]. 
Underground roadway engineering is influenced by factors, such as mining, surrounding rock conditions, and the roadway layout $[6,21,22]$. The above research provided a reference for tunnel engineering of the Lijiahao Coal Mine, but it cannot completely solve the practical problems of this mine. Thus, field measurements [23], theoretical analysis [24], and numerical simulations [25] were applied in this study to investigate the failure characteristics of the doublewithdrawal-channel surrounding rock at Panel 31113. In turn, a reasonable distance between the double-withdrawal channels was obtained. The research results will improve the efficiency of working face removal, preventing the failure of the surrounding rock and the arrangement of the withdrawal channel of the adjacent working face in the same mining area. In addition, this study will enable the realisation of safe and efficient mine production and the improvement of economic benefits [26-28].

\section{Working Face Overview and Mine Pressure Law}

2.1. Working Face Overview. The 31113 fully mechanised working face is located southwest of the Lijiahao Coal Mine, Dongsheng Coalfield in Ordos City, Inner Mongolia, Autonomous Region of China. The industrial plaza is arranged northeast. The goaf of the 31112 working face is directed northwards, and the solid coal is directed southwards.

Panel 31113 was located in the first panel of the 3-1 coal seam. The thickness of the coal seam was $4.4-5.3 \mathrm{~m}$. The structure was single, and the coal seam inclination angle was $0^{\circ}-3^{\circ}$. The average coal thickness in the mining area of the working face was $4.6 \mathrm{~m}$, and the area was a semidark coal region with complex joints and stable coal seams. The coal seam thickness in the entire working face was relatively stable and gradually increased from the return air channel to the main haulage channel. The thickness of the dirt bank near the cut hole was $0.04-0.1 \mathrm{~m}$. The thickness of the coal on the dirt bank was $4.2-4.3 \mathrm{~m}$, and that under the dirt bank was 0.3-0.6 $\mathrm{m}$. The dirt bank was relatively thin and did not affect recovery. The strike length of Panel 31113 was $3022 \mathrm{~km}$, and the inclined length was $300 \mathrm{~m}$. The working face was covered by the goaf of the $2-2 \#$ middle coal seam. The distance between the 3-1\# and 2-2\# coal seams was approximately $30-40 \mathrm{~m}$, and the buried depth was $215-225 \mathrm{~m}$. The direct roof lithology of Panel 31113 was mainly sandpaper mudstone. The basic roof was mainly fine-grained sandstone, and the immediate floor was sandpaper mudstone. The characteristics of the coal roof and floor are listed in Table 1.

\subsection{Leading Support Pressure Influence Range. Measurement} points were arranged on two mining roadways of a fully mechanised working face to monitor the surface displacement of the roadway to investigate the ore pressure advancement in the working face. Three measuring points were arranged in the air return roadway and transport roadway to determine the dynamic convergence of the roof, floor, and sides of the roadway during working face propulsion. The layout of the mine pressure monitoring points is shown in Figure 1.
When the working face was advanced to the observation point, four observations were made. The roadway deformation during each measurement was calculated based on the first observation of the roadway section. The monitoring results are obtained as follows.

As the distance between the working face and the observation point decreased, the displacements of the roof and floor at the observation point increased (Figures 2-4). When the working face advanced to the remaining $30 \mathrm{~m}$ from Point I, the displacement of the roof and floor was approximately $10 \mathrm{~mm}$ each. As the working face continues to advance, the displacement change increases to $55 \mathrm{~mm}$ when the distance from Point I remained $15 \mathrm{~m}$. When the working face advanced to the remaining $25 \mathrm{~m}$ from Point II, the roof and floor displacements were approximately $20 \mathrm{~mm}$. When the working face advanced to the remaining $5 \mathrm{~m}$ from Point II, the displacement increased to approximately $60 \mathrm{~mm}$. As the working face advanced further, the roof and floor variations at the three points also increased to approximately $60 \mathrm{~mm}$. From the monitoring results, it could be inferred that the range of the main transport groove significantly influenced by the working face was within $25 \mathrm{~m}$ in front of the working face.

The displacements of the roof, floor, and ribs at the observation point increased as the distance between the working face and the observation point decreased (Figures 5-7). When the working face advanced to approximately $35 \mathrm{~m}$ from Point $\mathrm{I}$, the displacements of the roof and floor were approximately $40 \mathrm{~mm}$. When the working face was approximately $10 \mathrm{~m}$ away from Point I, the displacements of the roof and floor increased to $105 \mathrm{~mm}$. Although the values for Points II and III were inconsistent, they exhibited the same trend as Point I values. Accordingly, the return air trough is influenced more by the working face than the main haulage channel. The scope of the auxiliary haulage channel that was severely affected by the working face was within $35 \mathrm{~m}$ of the working face.

Based on the above findings, it can be inferred that the influence range of the maximum support pressure of the 31113 fully mechanised working face was approximately 20-40 $\mathrm{m}$ before the working face.

\section{Numerical Simulation}

3.1. Model Establishment and Calculation Process. The failure characteristics of the surrounding rock and the reasonable spacing of the double-withdrawal channels were evaluated using FLAC3D numerical simulation software [29, 30]. The numerical simulations were performed using a three-dimensional mechanical model (Figure 8), and the mechanical parameters of the rock formation were determined (Table 2 ). The length ( $x$-direction) of the model was $700 \mathrm{~m}$, the width ( $y$-direction) was $600 \mathrm{~m}$, and the total height ( $z$-direction) was $130 \mathrm{~m}$. The plastic conditions reflected the Mohr-Coulomb strength criterion.

The model boundary conditions were as follows. The displacements in the $x$-direction on the left and right sections $(x=0, x=700)$ were limited to zero. The displacements in the $y$-direction on the front and back sections $(y=0$, $y=600$ ) were limited to zero. The degrees of freedom in the 
TABLE 1: Characteristics of coal roof and floor.

\begin{tabular}{lccc}
\hline Roof/floor & Rock name & $\begin{array}{c}\text { Min-Max } \\
\text { Average }(\mathrm{m})\end{array}$ & Lithology \\
\hline Main roof & Fine-grained sandstone, sandy mudstone & $10.13-23.13$ & $\begin{array}{c}\text { Grey, off-white, argillaceous cement with wavy } \\
\text { bedding containing plant leaf fossils. Flat fracture, } \\
\text { containing plant fossil fragments, microwave-like } \\
\text { bedding, with a slippery surface }\end{array}$ \\
\hline Immediate roof & Fine-grained sandstone, sandy mudstone & $\begin{array}{c}1.48-10.07 \\
5.78\end{array}$ & $\begin{array}{c}\text { Light grey, argillaceous silt-like structure, lenticular bedding, } \\
\text { and horizontal texture, containing mica plant fossils }\end{array}$ \\
\hline Immediate floor & Sandy mudstone & $\begin{array}{c}9.97-13 \\
11.5\end{array}$ & $\begin{array}{c}\text { Dark grey, uneven sand content, mica plant fossils, flat and } \\
\text { conchoidal fractures, horizontal texture }\end{array}$ \\
\hline
\end{tabular}

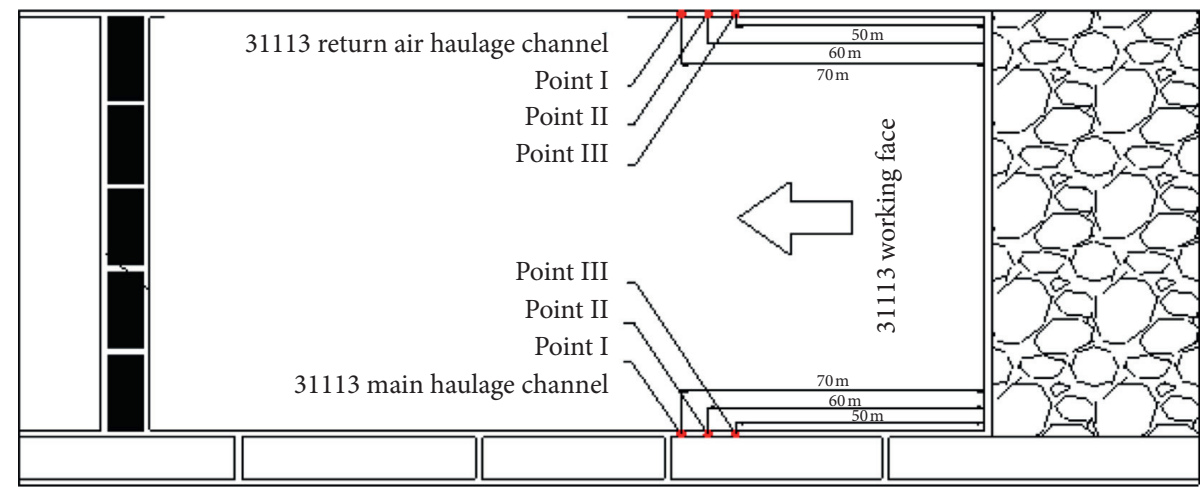

31113 auxiliary haulage channel

FIGURE 1: Layout of mine pressure monitoring points.

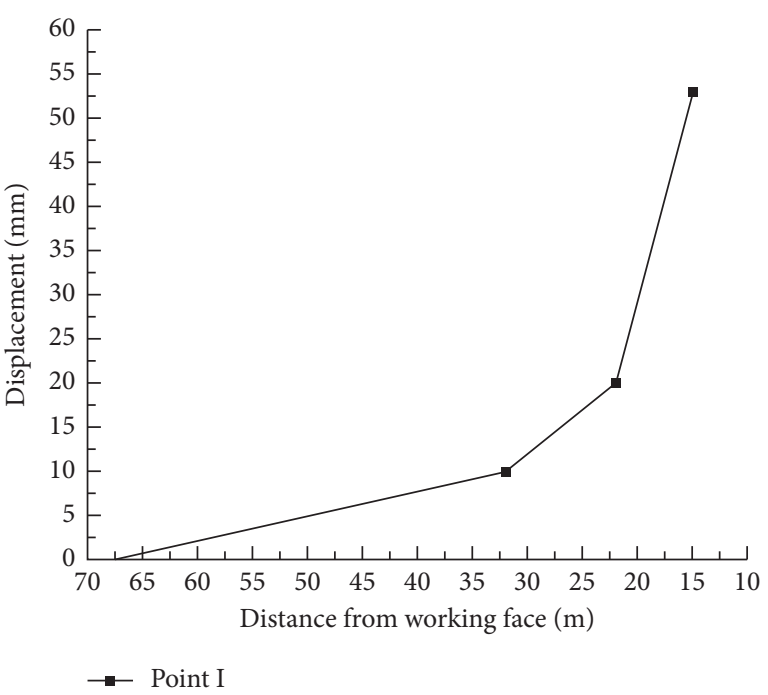

Figure 2: Displacements of roof and floor at Point I of main haulage channel.

three directions on the bottom horizontal plane were zero. The original rock stress acted on the uppermost horizontal plane $\sigma_{z}=\gamma h$, where $\gamma$ is the average weight of the overburden and $H$ is the total thickness of the overburden. From the average buried depth of the coal seam minus the thickness of the coal roof to the upper boundary of the model, $H=135 \mathrm{~m}$.

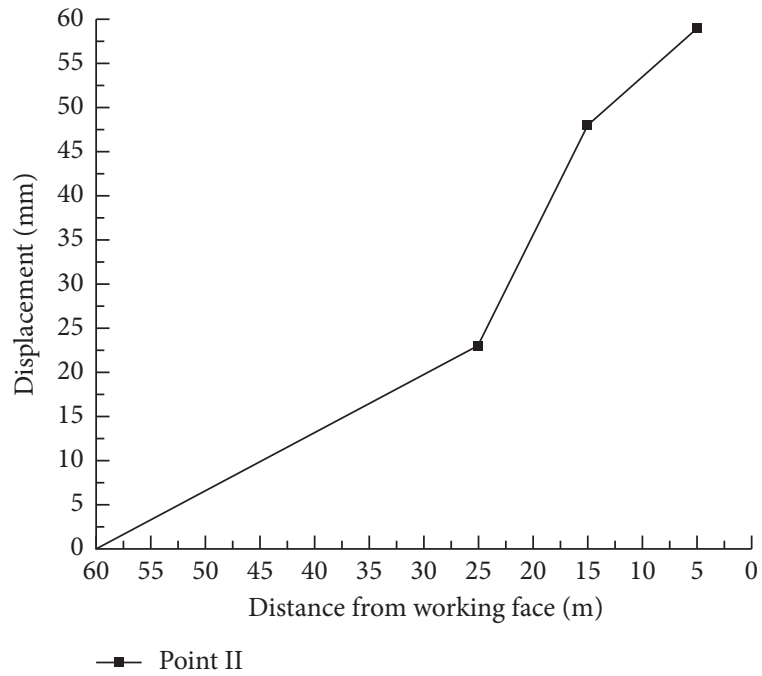

FIgURE 3: Displacements of roof and floor at Point II of main haulage channel.

3.2. Calculation Results Analysis. Based on the above analysis, the withdrawal channel was influenced by the mobile support pressure generated by the mining face as the working face advanced. The stress balance state generated during the roadway excavation stage was redistributed, owing to the effect of the advanced support pressure. The stress distribution characteristics of the working face at different distances from the main withdrawal channel were 


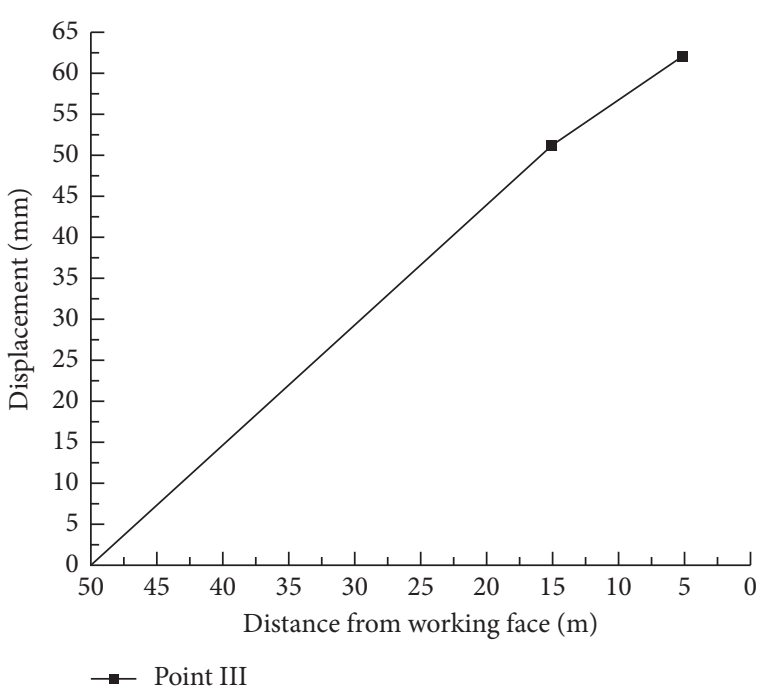

Figure 4: Displacements of roof and floor at Point III of main haulage channel.

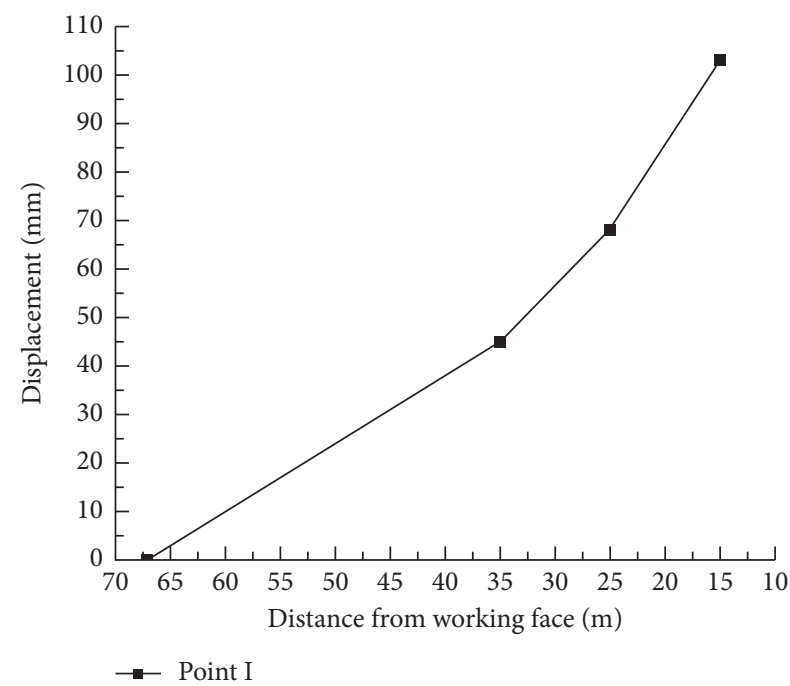

Figure 5: Displacements of roof and floor at Point I of auxiliary haulage channel.

analysed. The distances for the numerical analysis were 50 , $20,15,10,5$, and $0 \mathrm{~m}$. These cases are analysed as follows.

\subsubsection{Working Face Is $50 \mathrm{~m}$ away from Main Withdrawal} Channel. The principal stress and vertical stress distribution characteristics of the working face $50 \mathrm{~m}$ from the main retreat passage are shown in Figures 9 and 10 .

The shape and size of the stress field near the main and auxiliary withdrawal channels varied with different distances between the main and auxiliary withdrawal channels (Figures 9 and 10). When Panel 31113 was mined to the remaining $50 \mathrm{~m}$ away from the penetration, stress concentration occurred within 5-10 m of the working face, and the vertical and principal stresses tended to relax $15 \mathrm{~m}$ beyond the working face. At this time, the main and auxiliary withdrawals were far away from the working

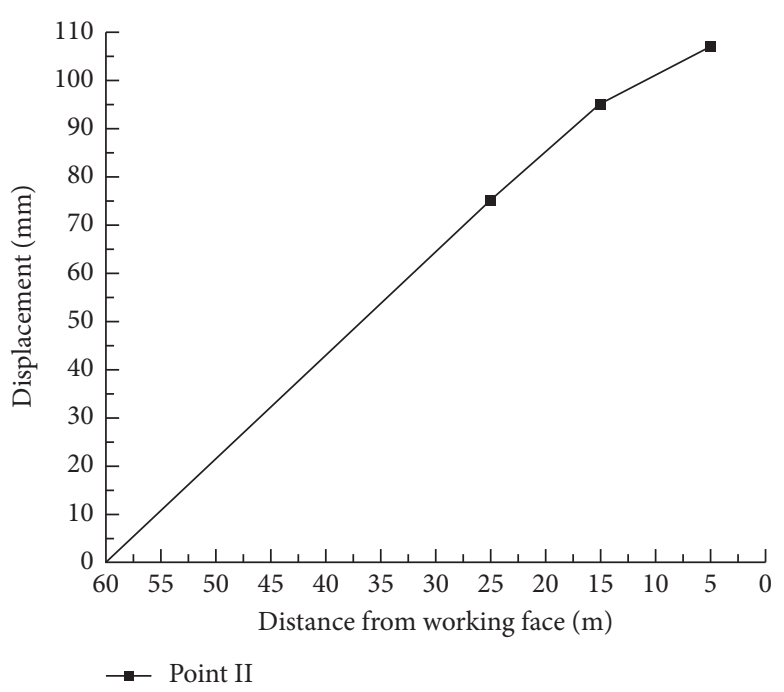

Figure 6: Displacements of roof and floor at Point II of auxiliary haulage channel.

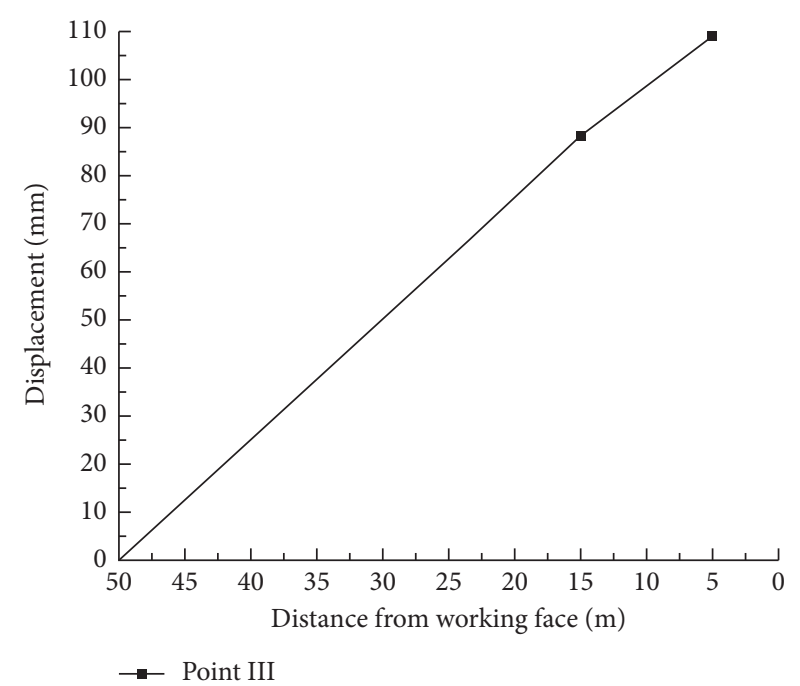

FIgURe 7: Displacements of roof and floor at Point III of auxiliary haulage channel.

face, so they were less affected by the mining of the working face. At $30 \mathrm{~m}$ between the main and auxiliary withdrawal channels, the vertical and maximum principal stresses of the main withdrawal front side reached the maximum values at $1.5 \mathrm{~m}$ in the coal body, and the maximum principal stress attained the maximum value at $10 \mathrm{~m}$ in the coal body. The vertical stress of the main withdrawal secondary side reached the maximum at $1.2 \mathrm{~m}$ in the coal body, and the maximum principal stress attained the maximum at $10 \mathrm{~m}$ in the coal body. Moreover, the vertical and maximum principal stresses of the auxiliary channel secondary side reached the maximum at $1.5 \mathrm{~m}$ in the coal body, and the maximum principal stress reached the maximum at $10 \mathrm{~m}$ in the coal body. At $25 \mathrm{~m}$ between the main and auxiliary withdrawal channels, the force of the main withdrawal front side did not change 


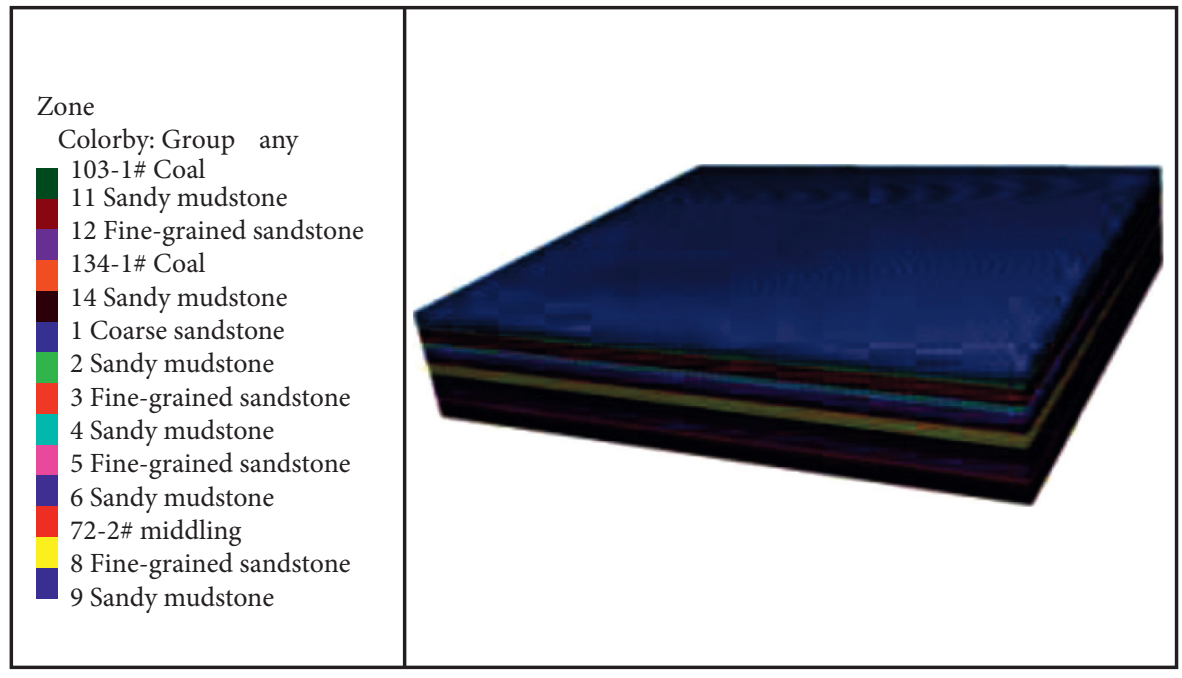

FIgURE 8: FLAC3D mining numerical simulation model.

TABLE 2: Mechanical parameters of rock formation.

\begin{tabular}{|c|c|c|c|c|c|c|}
\hline Parameter lithology & Density $\left(\mathrm{kg} / \mathrm{m}^{3}\right)$ & Bulk modulus (GPa) & Shear modulus (GPa) & Internal friction angle $\left({ }^{\circ}\right)$ & Cohesion $(\mathrm{MPa})$ & Tensile strength $(\mathrm{MPa})$ \\
\hline Sandy mudstone & 2300 & 0.73 & 0.75 & 32 & 2.5 & 1.65 \\
\hline Fine-grained sandstone & 2500 & 2.53 & 3.78 & 33 & 3.0 & 1.75 \\
\hline Sandy mudstone & 2400 & 3.8 & 1.8 & 28 & 2.1 & 1.7 \\
\hline $2-2$ middling & 1350 & 0.16 & 0.4 & 25 & 1.2 & 1.2 \\
\hline Sandy mudstone & 2400 & 3.2 & 2.6 & 27 & 1.3 & 1.1 \\
\hline Fine-grained sandstone & 2500 & 2.53 & 3.78 & 31 & 2.5 & 1.7 \\
\hline Sandy mudstone & 2400 & 3.2 & 2.6 & 27 & 1.3 & 1.1 \\
\hline 3-1 middling & 1400 & 1.19 & 0.38 & 28 & 1.6 & 1.03 \\
\hline Sandy mudstone & 2600 & 3.9 & 1.9 & 31 & 1.5 & 1.3 \\
\hline Fine-grained sandstone & 2500 & 2.53 & 3.7 & 31 & 2.5 & 1.7 \\
\hline $4-1$ coal & 1500 & 3.48 & 1.61 & 34.45 & 1.43 & 0.92 \\
\hline
\end{tabular}

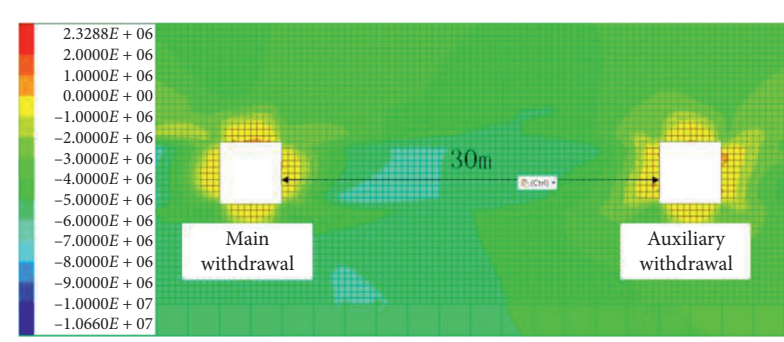

Minimum principal stress cloud diagram

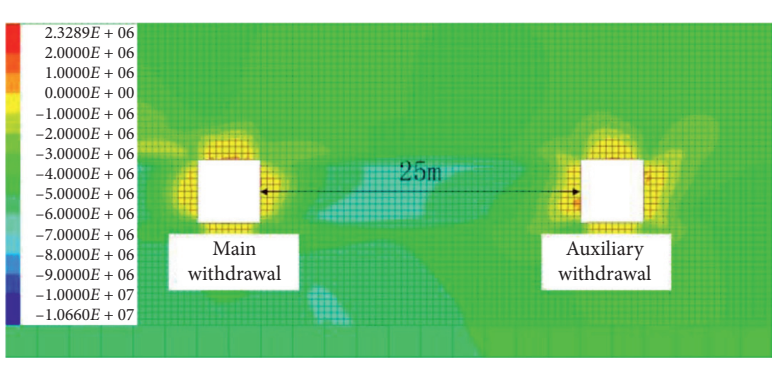

Minimum principal stress cloud diagram

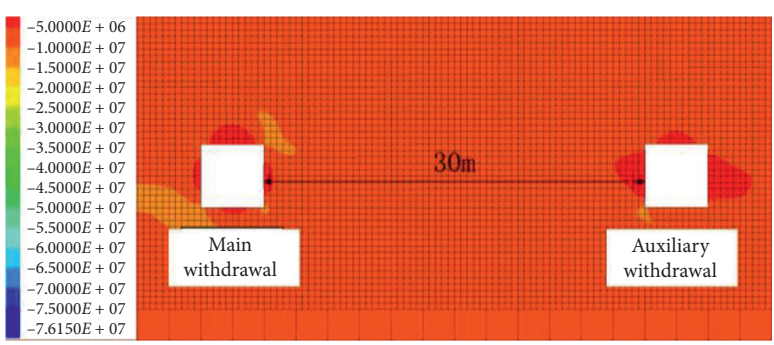

Maximum principal stress cloud diagram

(a)

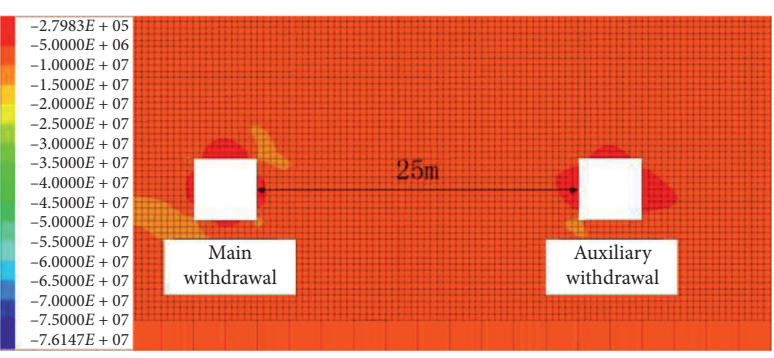

Maximum principal stress cloud diagram

(b)

Figure 9: Continued. 


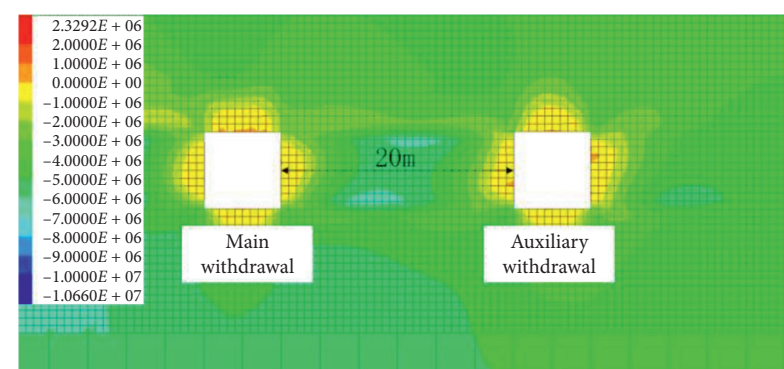

Minimum principal stress cloud diagram

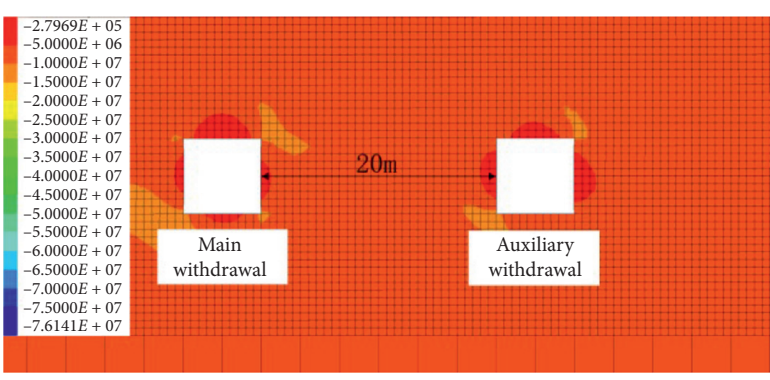

Maximum principal stress cloud diagram

(c)

FIgURE 9: Principal stress cloud diagrams when Panel 31113 was $50 \mathrm{~m}$ from penetration. (a) Main and auxiliary withdrawal spacing $=30 \mathrm{~m}$. (b) Main and auxiliary withdrawal spacing $=25 \mathrm{~m}$. (c) Main and auxiliary withdrawal spacing $=20 \mathrm{~m}$.

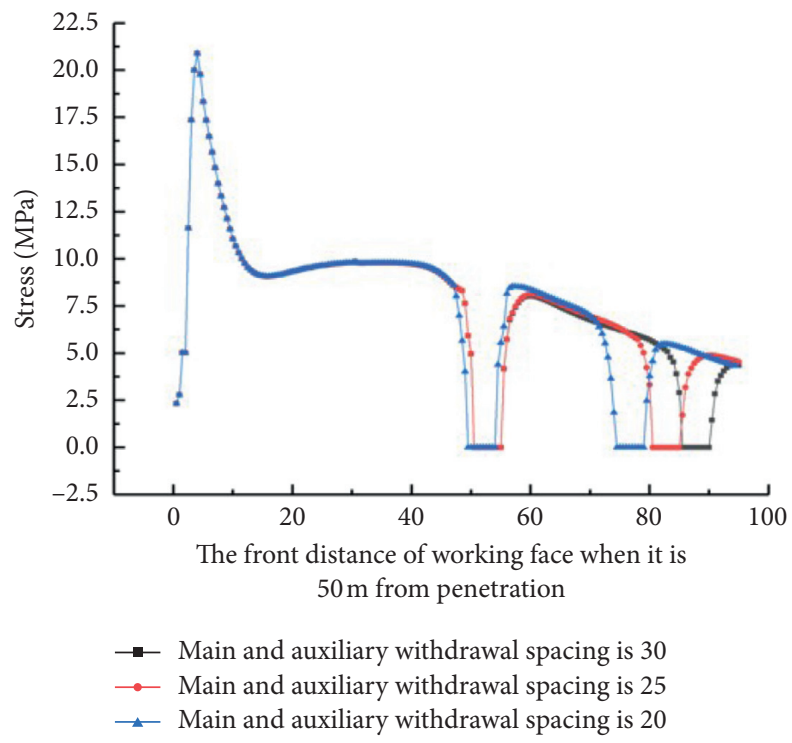

Figure 10: Vertical stress curve when Panel 31113 is $50 \mathrm{~m}$ from penetration.

significantly. The vertical and maximum principal stresses of the auxiliary channel acted at $1.5 \mathrm{~m}$ in the coal body, and the minimum principal stress existed at $10 \mathrm{~m}$ in the coal body. When the distance between the main and auxiliary withdrawal channels was $20 \mathrm{~m}$, no significant change in the force on the front side of the main withdrawal was observed. The vertical and maximum principal stresses of the auxiliary withdrawal acted at $1.5 \mathrm{~m}$ in the coal body, and the minimum principal stress was at $10 \mathrm{~m}$ in the coal body. The vertical stress and maximum principal stress of the auxiliary withdrawal front side acted at $1.5 \mathrm{~m}$ in the coal body, and the minimum principal stress did not change. The mining effect of the working face was mainly concentrated within $15 \mathrm{~m}$ in front of the working face. It had a minimal effect on the withdrawal channel when the working face was far away.

3.2.2. Working Face Is $20 \mathrm{~m}$ away from Main Withdrawal Channel. The principal and vertical stress distribution characteristics of the working face $50 \mathrm{~m}$ from the main retreat passage are depicted in Figures 11 and 12.
Figure 11 shows the maximum and minimum principal stress cloud diagram when working face 31113 distance is $50 \mathrm{~m}$ from penetration.

When Panel 31113 was mined to $20 \mathrm{~m}$ from the penetration and the main and auxiliary withdrawal channels were $30 \mathrm{~m}$ apart, the vertical and maximum principal stresses of the main withdrawal front side peaked at $2 \mathrm{~m}$ in the coal body, and the maximum principal stress reaches the above figure at $10 \mathrm{~m}$ in the coal body (Figures 11 and 12). The vertical and maximum principal stresses of the main withdrawal secondary side peaked at $2 \mathrm{~m}$ in the coal body, and the maximum principal stress attained the maximum value at $10 \mathrm{~m}$ in the coal body. The vertical and maximum principal stresses of the auxiliary withdrawal secondary side peaked at $2.5 \mathrm{~m}$ in the coal body, and the maximum principal stress reached the upper limit at $10 \mathrm{~m}$ in the coal body. The vertical and maximum principal stresses on the auxiliary withdrawal front side peaked at $2 \mathrm{~m}$ in the coal body, and the maximum principal stress reached the maximum value at $10 \mathrm{~m}$ in the coal body. At $25 \mathrm{~m}$ between the main and auxiliary withdrawal channels, the main withdrawal stress value did not change significantly. The vertical and maximum principal stresses of the auxiliary withdrawal and 


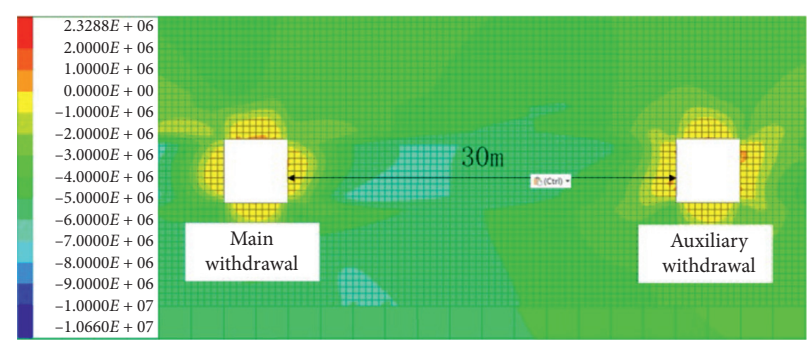

Minimum principal stress cloud diagram

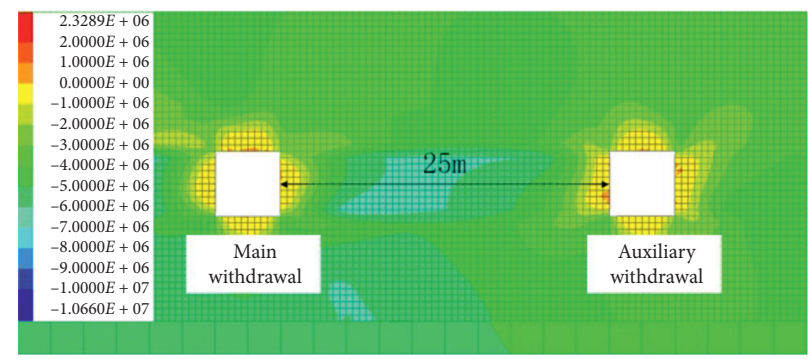

Minimum principal stress cloud diagram

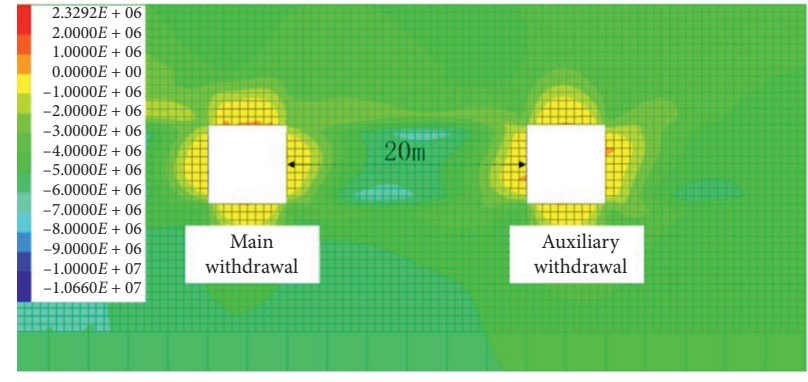

Minimum principal stress cloud diagram

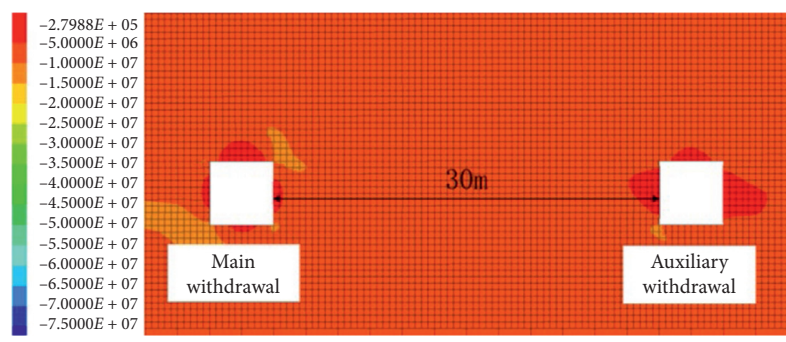

Maximum principal stress cloud diagram

(a)

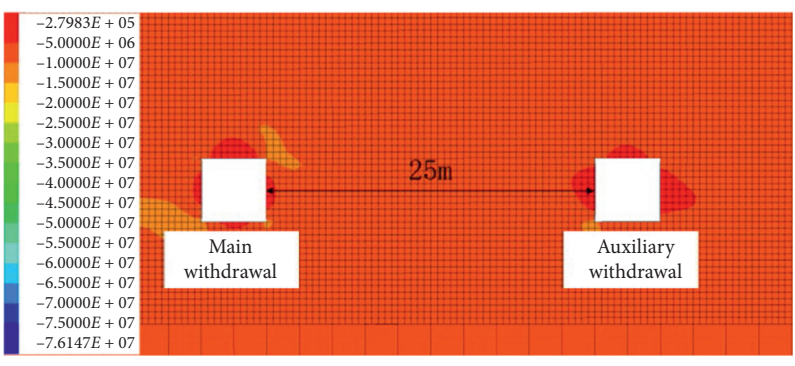

Maximum principal stress cloud diagram

(b)

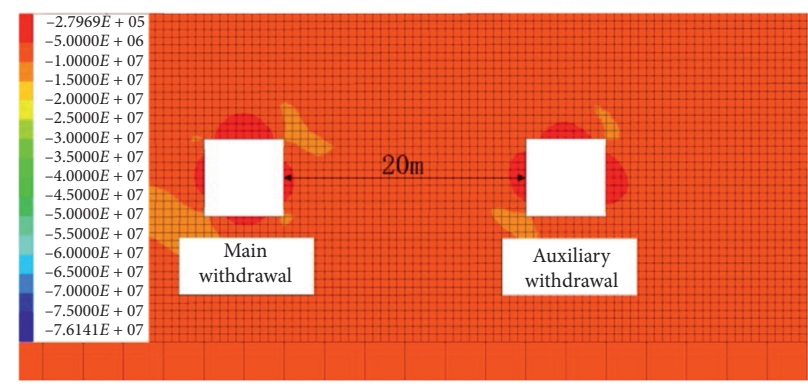

Maximum principal stress cloud diagram

(c)

Figure 11: Principal stress cloud diagrams when Panel 31113 distance was $20 \mathrm{~m}$ from penetration. (a) When the main and auxiliary withdrawal spacing is $30 \mathrm{~m}$, (b) when the main and auxiliary withdrawal spacing is $25 \mathrm{~m}$, and (c) when the main and auxiliary withdrawal spacing is $20 \mathrm{~m}$.

auxiliary side peaked at $2.5 \mathrm{~m}$ in the coal body, and the maximum principal stress reached the highest value at $10 \mathrm{~m}$ in the coal body. The vertical and maximum principal stresses of the auxiliary withdrawal channel front side peaked at $2 \mathrm{~m}$ in the coal body, and the maximum principal stress attained the highest value at $10 \mathrm{~m}$ in the coal body. At $20 \mathrm{~m}$ between the main and auxiliary withdrawal channels, the main withdrawal stress value did not change considerably. The vertical and maximum principal stresses of the auxiliary withdrawal and secondary side reached their peak at $2.5 \mathrm{~m}$ in the coal body, and the maximum principal stress reached the maximum value at $10 \mathrm{~m}$ in the coal body. The vertical stress and maximum principal stress of the auxiliary withdrawal front side reached the maximum value at $2 \mathrm{~m}$ in the coal body, and the maximum principal stress peaked at $10 \mathrm{~m}$ in the coal body. At this point, the main withdrawal front side began to be affected by mining.

3.2.3. Working Face Is $15 \mathrm{~m}$ away from Main Withdrawal Channel. The principal and vertical stress distribution characteristics of the working face $50 \mathrm{~m}$ from the main retreat passage are depicted in Figures 13 and 14.

When Panel 31113 was mined to $15 \mathrm{~m}$ away from the penetration, the main withdrawal started penetrating the severely affected area $15 \mathrm{~m}$ ahead of the working face mining. At $30 \mathrm{~m}$ between the main and auxiliary withdrawal channels, the vertical and maximum principal stresses of the main withdrawal acted at $2 \mathrm{~m}$ in the coal body, and the maximum principal stress attained the maximum value at $7.5 \mathrm{~m}$ in the coal body. The vertical and maximum principal stresses of the main withdrawal and auxiliary side peaked at $2 \mathrm{~m}$ in the coal body, and the maximum principal stress reached the highest value at $10 \mathrm{~m}$ in the coal body. The vertical and maximum principal stresses of the auxiliary withdrawal secondary side reached the peak at $2.5 \mathrm{~m}$ in the coal body, and the maximum principal stress attained the maximum at $10 \mathrm{~m}$ in the coal body. Moreover, the vertical and maximum principal stresses of the auxiliary withdrawal front side peaked at $2 \mathrm{~m}$ in the coal body. At $25 \mathrm{~m}$ between the main and auxiliary withdrawal channels, the main 


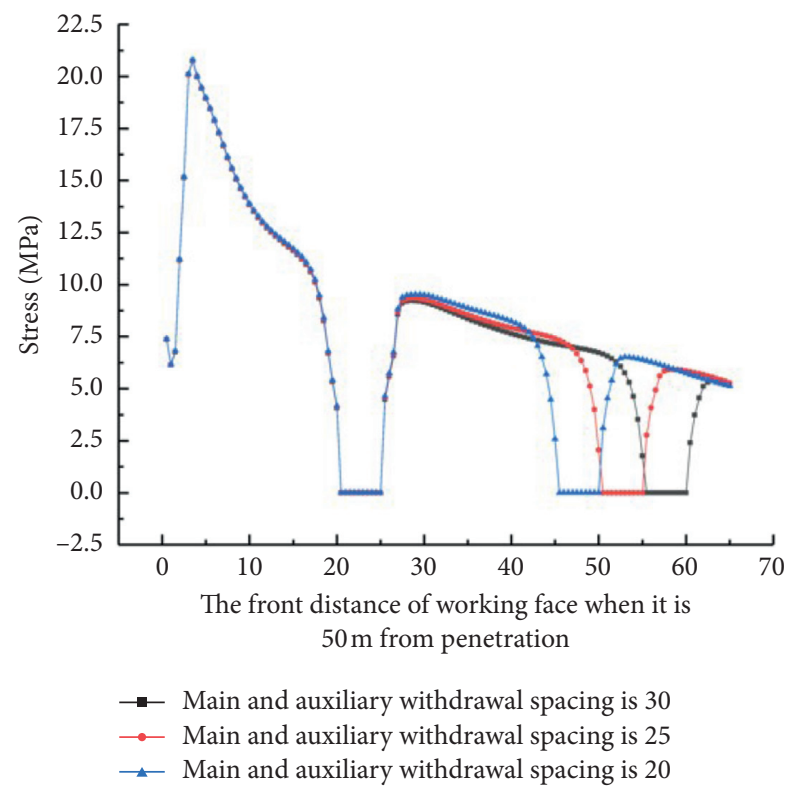

Figure 12: Vertical stress curve when Panel 31113 is $20 \mathrm{~m}$ from penetration.

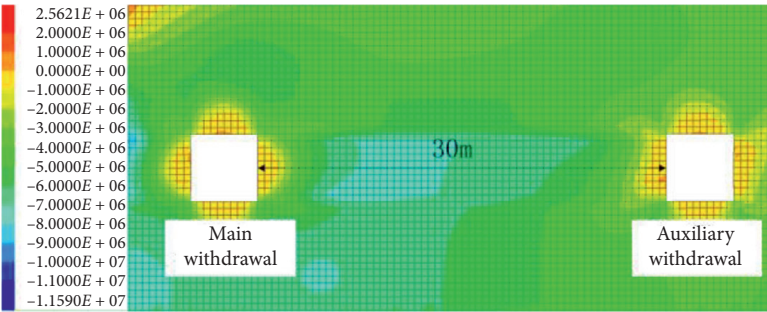

Minimum principal stress cloud diagram

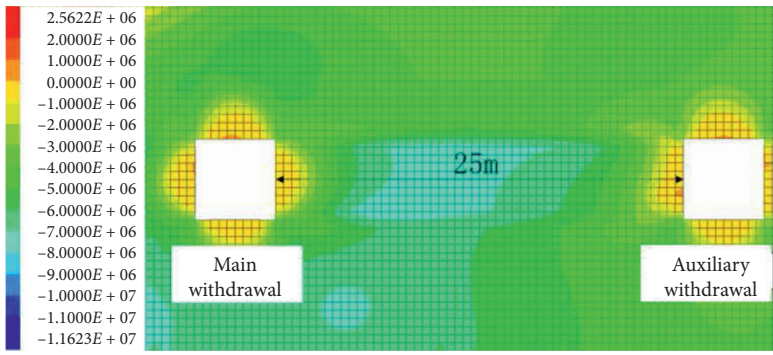

Minimum principal stress cloud diagram

(b)

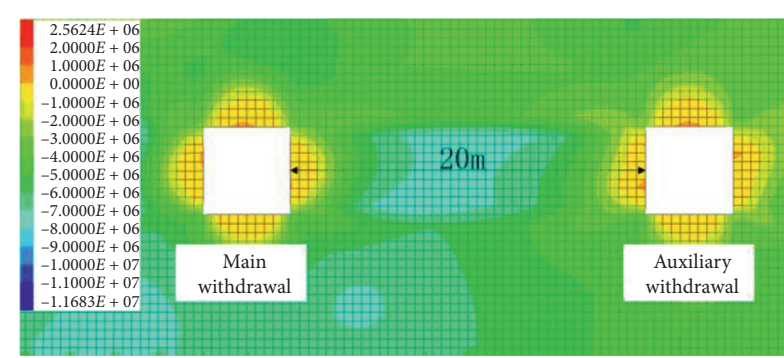

Minimum principal stress cloud diagram

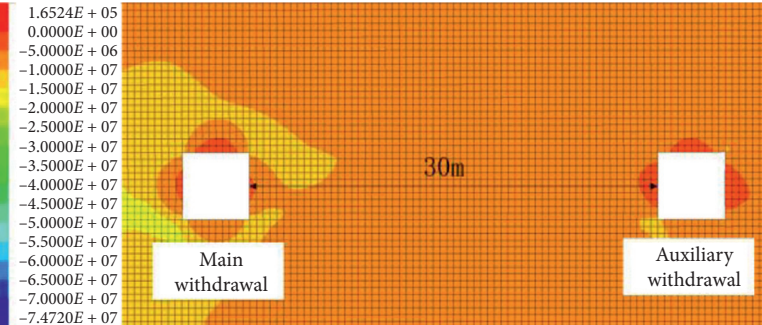

Maximum principal stress cloud diagram

(a)

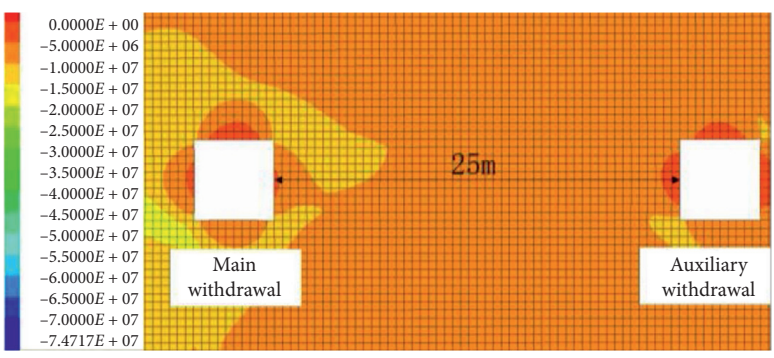

Maximum principal stress cloud diagram

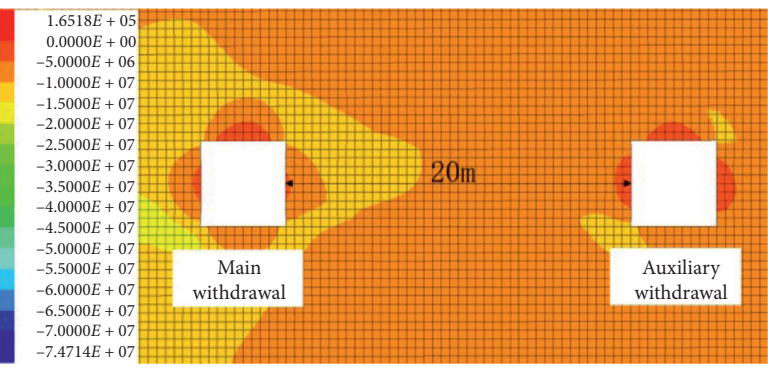

Maximum principal stress cloud diagram

(c)

FIgURE 13: Maximum and minimum principal stress cloud diagrams when Panel 31113 was $15 \mathrm{~m}$ from penetration. (a) Main and auxiliary withdrawal spacing $=30 \mathrm{~m}$. (b) Main and auxiliary withdrawal spacing $=25 \mathrm{~m}$. (c) Main and auxiliary withdrawal spacing $=20 \mathrm{~m}$. 


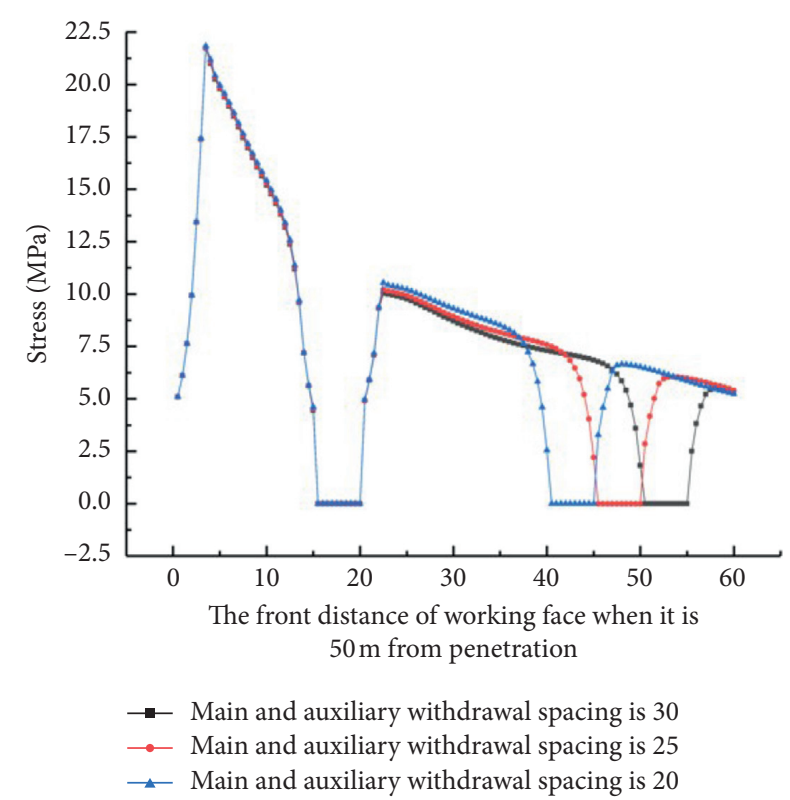

Figure 14: Vertical stress curve when Panel 31113 is $15 \mathrm{~m}$ from penetration.

withdrawal stress value did not change significantly. The vertical and maximum principal stresses of the auxiliary withdrawal secondary side peaked at $2.5 \mathrm{~m}$ in the coal body, and the maximum principal stress attained the maximum value at $10 \mathrm{~m}$ in the coal body. The vertical and maximum principal stresses of the auxiliary withdrawal front side peaked at $2 \mathrm{~m}$ in the coal body, and the maximum principal stress reached the highest value at $10 \mathrm{~m}$ in the coal body. At $20 \mathrm{~m}$ between the main and auxiliary withdrawal channels, the main withdrawal stress value did not change significantly. The vertical and maximum principal stress of the auxiliary withdrawal secondary side peaked at $2.5 \mathrm{~m}$ in the coal body, and the maximum principal stress reached the maximum value at $10 \mathrm{~m}$ in the coal body. The vertical and maximum principal stresses of the auxiliary withdrawal peaked at $2 \mathrm{~m}$ in the coal body, and the maximum principal stress attained the highest value at $10 \mathrm{~m}$ in the coal body. The main withdrawal front side was then influenced by the mining face.

3.2.4. Working Face Is $10 \mathrm{~m}$ away from Main Withdrawal Channel. The principal and vertical stress distribution characteristics of the working face $50 \mathrm{~m}$ from the main retreat passage are shown in Figures 15 and 16.

When Panel 31113 was mined to $10 \mathrm{~m}$ away from the penetration, the main withdrawal penetrated the severely affected range of the advanced supporting pressure generated by the working face mining. When the main and auxiliary withdrawal channels were separated by $30 \mathrm{~m}$, the vertical and maximum principal stresses of the main withdrawal front side acted at $4 \mathrm{~m}$ in the coal body, and the maximum principal stress reached the highest value at $5 \mathrm{~m}$ in the coal body. The vertical and maximum principal stresses of the main withdrawal secondary side peaked at $2 \mathrm{~m}$ in the coal body, and the maximum principal stress reached the maximum value at $10 \mathrm{~m}$ in the coal body. The vertical stress and maximum principal stress of the auxiliary withdrawal secondary side peaked at $2.5 \mathrm{~m}$ in the coal body, and the maximum principal stress reached the maximum value at $10 \mathrm{~m}$ in the coal body. Furthermore, the vertical and maximum principal stresses of the auxiliary withdrawal front side peaked at $2 \mathrm{~m}$ in the coal body. At $25 \mathrm{~m}$ between the main and auxiliary withdrawal channels, the main withdrawal stress value did not change significantly. The vertical and maximum principal stresses of the auxiliary withdrawal secondary side peaked at $2.5 \mathrm{~m}$ in the coal body, and the maximum principal stress reached the highest value at $10 \mathrm{~m}$ in the coal body. The vertical and maximum principal stresses of the auxiliary withdrawal front side peaked at $2 \mathrm{~m}$ in the coal body, and the maximum principal stress attained the highest value at $10 \mathrm{~m}$ in the coal body. At $20 \mathrm{~m}$ between the main and auxiliary withdrawal channels, the main withdrawal stress value did not change considerably. The vertical and maximum principal stresses of the auxiliary withdrawal secondary side peaked at $2.5 \mathrm{~m}$ in the coal body, and the maximum principal stress attained the maximum at $10 \mathrm{~m}$ in the coal body. The vertical and maximum principal stresses of the auxiliary withdrawal front side peaked at $2 \mathrm{~m}$ in the coal body, and the maximum principal stress reached the upper limit at $10 \mathrm{~m}$ in the coal body. The main withdrawal front side was severely affected by the working face mining, and the secondary side also entered into the severely affected area of the working face mining.

\subsubsection{Working Face Is $5 \mathrm{~m}$ away from Main Withdrawal} Channel. The principal and vertical stress distribution characteristics of the working face $50 \mathrm{~m}$ from the main retreat passage are depicted in Figures 17 and 18.

The peak support pressure generated by the working face was transferred to the main withdrawal and secondary side when Panel 31113 was mined to $5 \mathrm{~m}$ away from the penetration. When the main and auxiliary withdrawal channels were $30 \mathrm{~m}$ apart, the vertical and maximum principal stresses of the main withdrawal front side decreased, indicating that the front side of the coal body was wholly damaged and lost its bearing capacity. The vertical and maximum principal stresses of the main withdrawal and secondary side peaked at $3 \mathrm{~m}$ in the coal body, and the maximum principal stress reached the maximum value at $10 \mathrm{~m}$ in the coal body. The vertical and maximum principal stresses of the auxiliary withdrawal secondary side reached a peak value at $2.5 \mathrm{~m}$ in the coal body, and the maximum principal stress attained the maximum at $10 \mathrm{~m}$ in the coal body. Additionally, the vertical and maximum principal stresses of the auxiliary withdrawal front side peaked at $2 \mathrm{~m}$ in the coal body. At $25 \mathrm{~m}$ between the main and auxiliary withdrawal channels, the main withdrawal stress between the main and auxiliary withdrawal channels did not change significantly. The vertical and maximum principal stresses of the auxiliary withdrawal and secondary side peaked at $2.5 \mathrm{~m}$ 


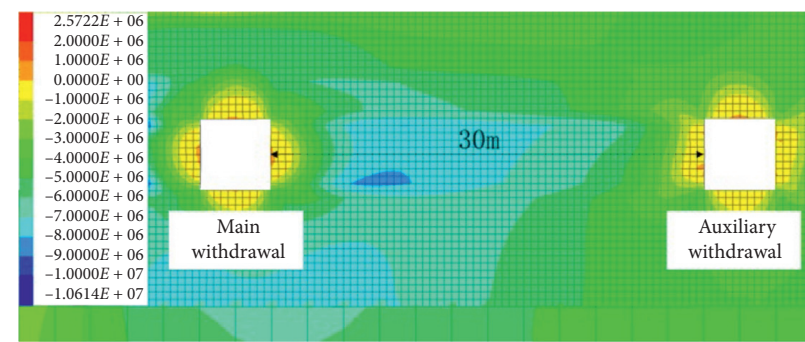

Minimum principal stress cloud diagram

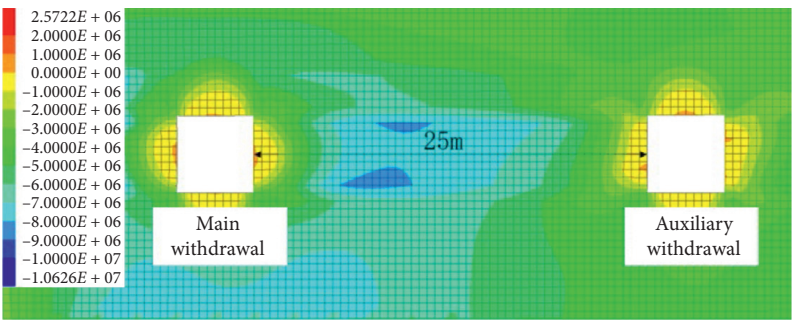

Minimum principal stress cloud diagram

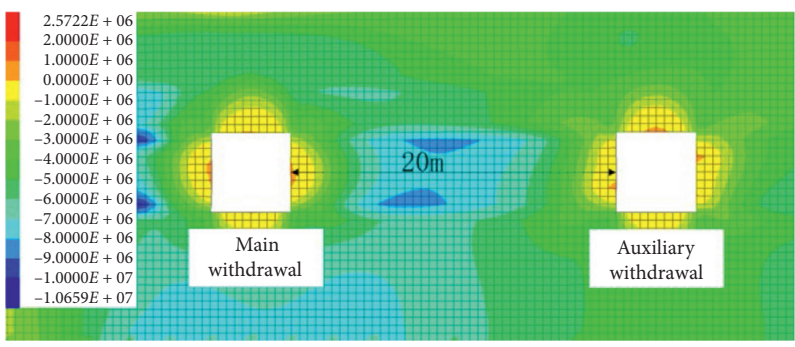

Minimum principal stress cloud diagram

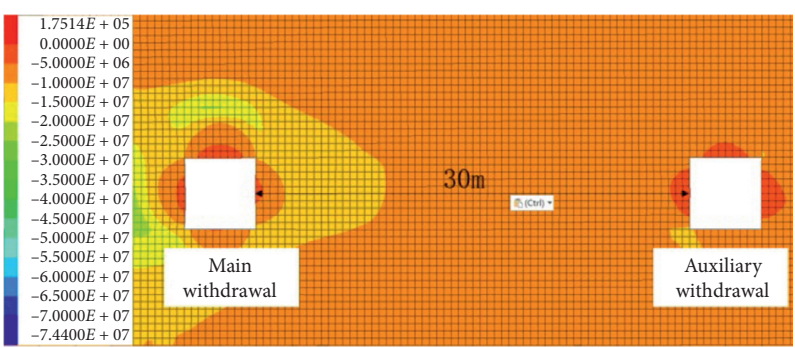

Maximum principal stress cloud diagram

(a)

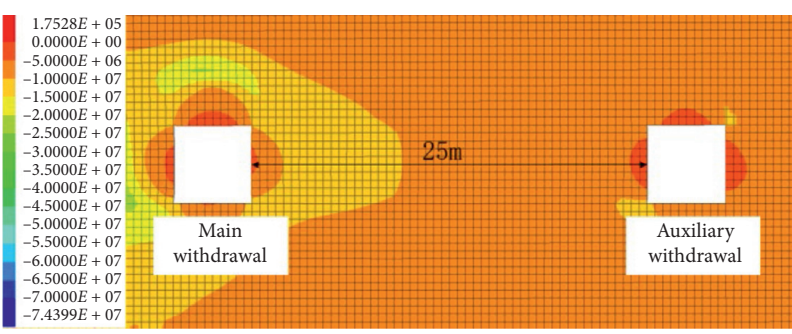

Maximum principal stress cloud diagram

(b)

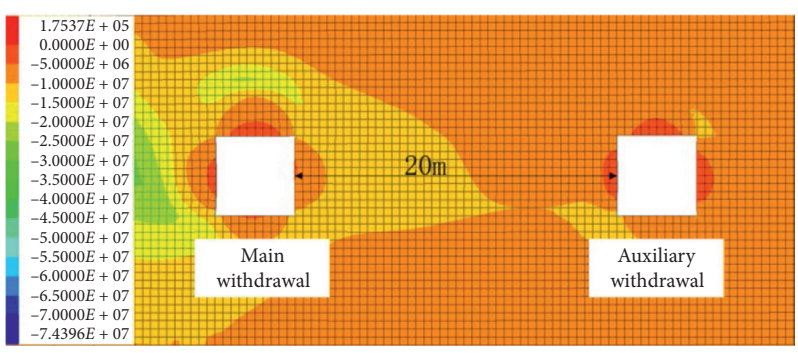

Maximum principal stress cloud diagram

(c)

Figure 15: Maximum and minimum principal stress cloud diagrams when Panel 31113 is $10 \mathrm{~m}$ from penetration. (a) When the main and auxiliary withdrawal spacing is $30 \mathrm{~m}$, (b) when the main and auxiliary withdrawal spacing is $25 \mathrm{~m}$, and (c) when the main and auxiliary withdrawal spacing is $20 \mathrm{~m}$.

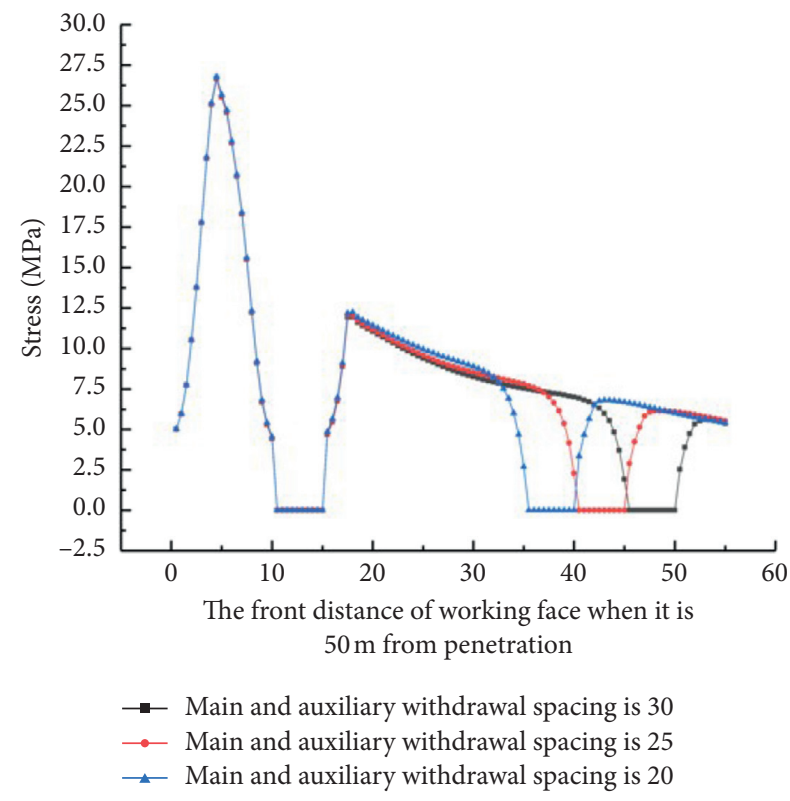

Figure 16: Vertical stress curve when Panel 31113 is $10 \mathrm{~m}$ from penetration. in the coal body, and the maximum principal stress attained the highest limit at $10 \mathrm{~m}$ in the coal body. The vertical and maximum principal stresses of the auxiliary withdrawal front side peaked at $2 \mathrm{~m}$ in the coal body, and the maximum principal stress reached the maximum value at $10 \mathrm{~m}$ in the coal body. At $20 \mathrm{~m}$ between the main and auxiliary withdrawal channels, the main withdrawal stress value did not change considerably. The vertical and maximum principal stresses of the auxiliary withdrawal and secondary side peaked at $2.5 \mathrm{~m}$ in the coal body, and the maximum principal stress reached the highest value at $10 \mathrm{~m}$ in the coal body. The vertical and maximum principal stresses of the auxiliary withdrawal front side peaked at $2 \mathrm{~m}$ in the coal body, and the maximum principal stress reached the highest limit at $10 \mathrm{~m}$ in the coal body. The main withdrawal channel secondary and auxiliary withdrawal front sides were severely affected by the mining, increasing with a decreasing distance between the main and auxiliary withdrawal channels. The shape of the stress curve for $20 \mathrm{~m}$ between the main and auxiliary withdrawal channels changed to a single-peak shape. 


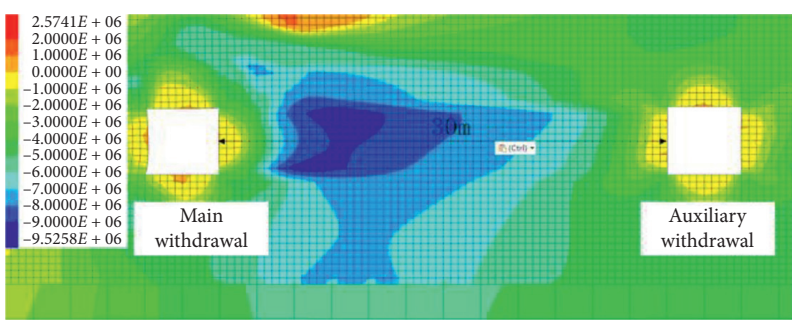

Minimum principal stress cloud diagram

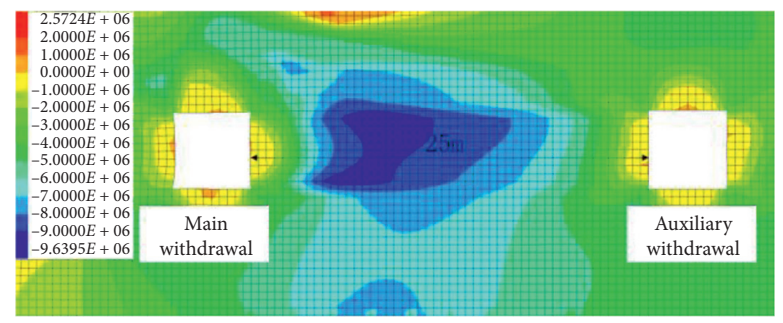

Minimum principal stress cloud diagram

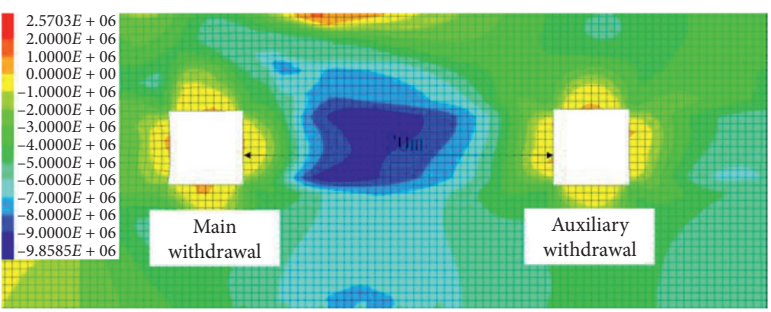

Minimum principal stress cloud diagram

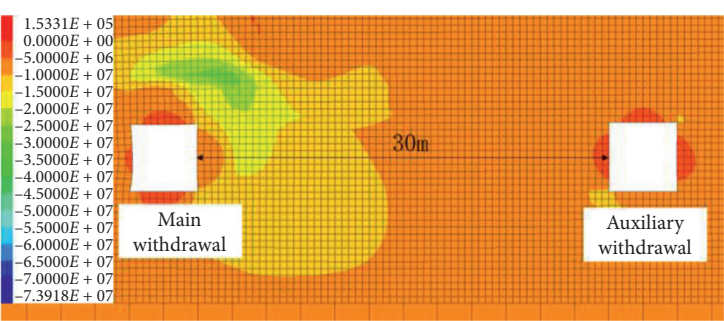

Maximum principal stress cloud diagram

(a)

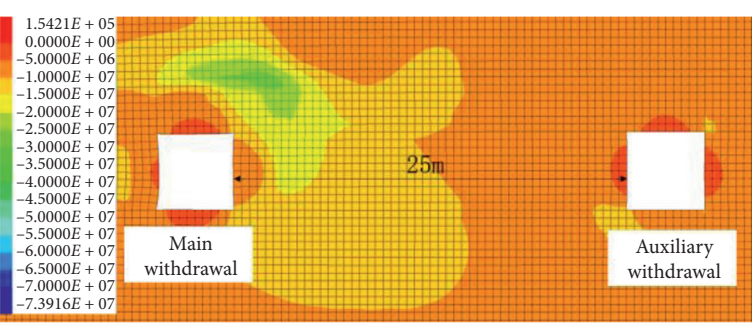

Maximum principal stress cloud diagram

(b)

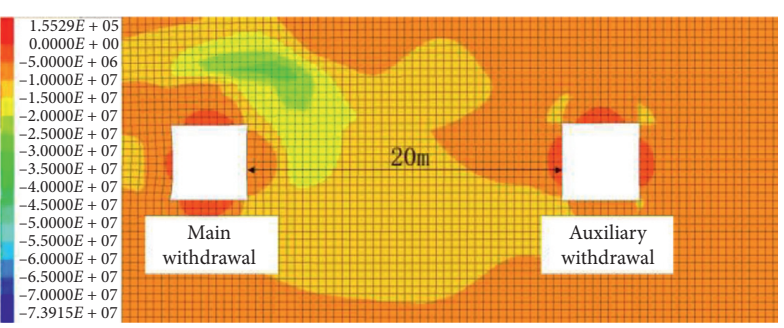

Maximum principal stress cloud diagram

(c)

Figure 17: Maximum and minimum principal stress cloud diagram when Panel 31113 is $5 \mathrm{~m}$ from penetration. (a) Main and auxiliary withdrawal spacing $=30 \mathrm{~m}$. (b) Main and auxiliary withdrawal spacing $=25 \mathrm{~m}$. (c) Main and auxiliary withdrawal spacing $=20 \mathrm{~m}$.

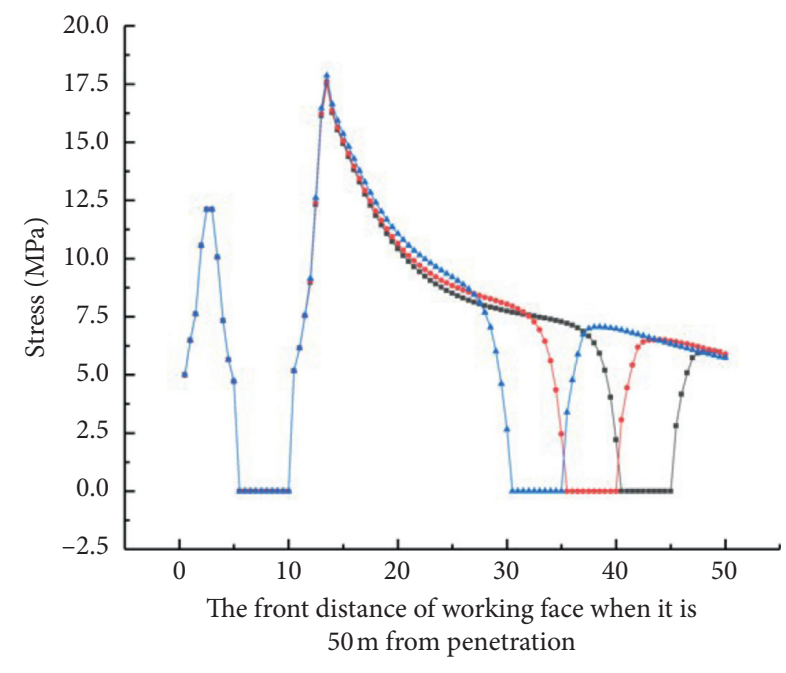

$\rightarrow-$ Main and auxiliary withdrawal spacing is 30

- Main and auxiliary withdrawal spacing is 25

$\ldots$ Main and auxiliary withdrawal spacing is 20

Figure 18: Vertical stress curve when Panel 31113 is $5 \mathrm{~m}$ from penetration.
3.2.6. Working Face Is $0 \mathrm{~m}$ away from Main Withdrawal Channel. The principal and vertical stress distribution characteristics of the working face $50 \mathrm{~m}$ from the main retreat passage are shown in Figures 19 and 20.

When Panel 31113 was penetrated, the peak support pressure generated by working face mining continued to shift to the main withdrawal and auxiliary channel depths. When the main and auxiliary withdrawal channels were $30 \mathrm{~m}$ apart, the vertical and maximum principal stresses of the main withdrawal auxiliary side peaked at $3 \mathrm{~m}$ in the coal body, and the maximum principal stress reached its maximum at $10 \mathrm{~m}$ in the coal body. The vertical and maximum principal stresses of the auxiliary withdrawal secondary side peaked at $2.5 \mathrm{~m}$ in the coal body, and the maximum principal stress reached a maximum value at $10 \mathrm{~m}$ in the coal body. The vertical and maximum principal stresses of the auxiliary withdrawal front side peaked at $2 \mathrm{~m}$ in the coal body. At $25 \mathrm{~m}$ between the main and auxiliary withdrawal channels, the main withdrawal stress value did not change significantly. The vertical and maximum principal stresses of the auxiliary withdrawal secondary side peaked at $2.5 \mathrm{~m}$ in the coal body, and the maximum principal stress reached its maximum at $10 \mathrm{~m}$ in the coal body. The vertical and maximum principal 


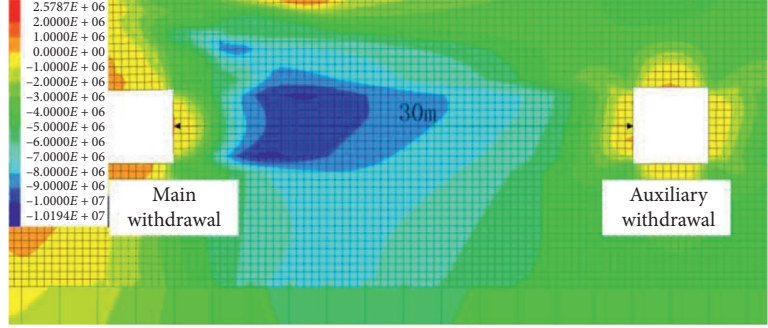

Minimum principal stress cloud diagram

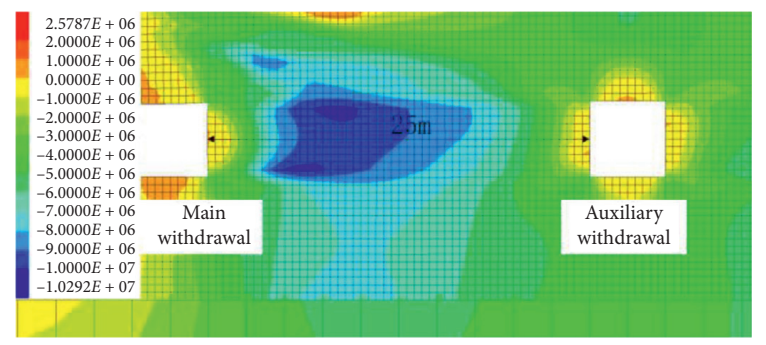

Minimum principal stress cloud diagram

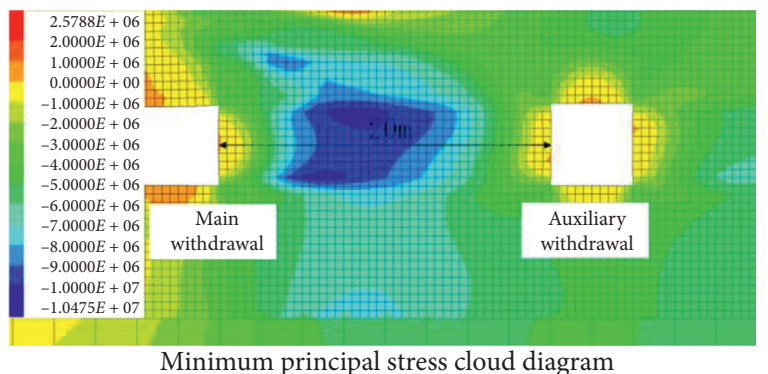

Minimum principal stress cloud diagram

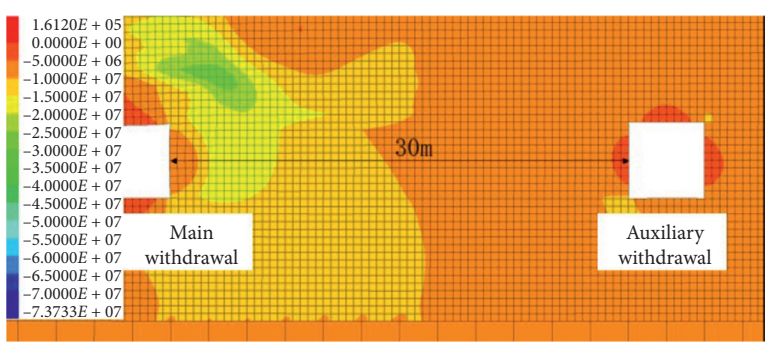

Maximum principal stress cloud diagram

(a)

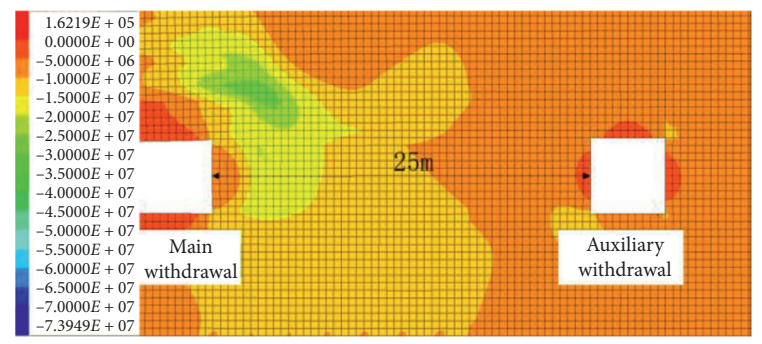

Maximum principal stress cloud diagram

(b)

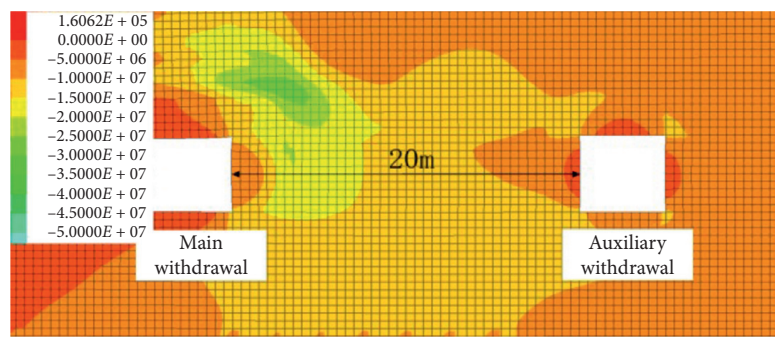

Maximum principal stress cloud diagram

(c)

Figure 19: Maximum and minimum principal stress cloud diagrams when Panel 31113 is penetrated. (a) Main and auxiliary withdrawal spacing $=30 \mathrm{~m}$. (b) Main and auxiliary withdrawal spacing $=25 \mathrm{~m}$. (c) Main and auxiliary withdrawal spacing $=20 \mathrm{~m}$.

stresses of the auxiliary withdrawal front side peaked at $2 \mathrm{~m}$ in the coal body, and the maximum principal stress reached its highest value at $10 \mathrm{~m}$ in the coal body. At $20 \mathrm{~m}$ between the main and auxiliary withdrawal channels, the main withdrawal stress value did not change remarkably, and the auxiliary withdrawal and secondary sides entered the severe influence range of the mining face. Here, the vertical and maximum principal stress peaked, and the maximum principal stress reached the highest value at $10 \mathrm{~m}$ in the coal body. The vertical and maximum principal stresses of the auxiliary withdrawal front side peaked at $2 \mathrm{~m}$ in the coal body, and the maximum principal stress reached the maximum value at $10 \mathrm{~m}$ in the coal body. Both the auxiliary withdrawal front and secondary sides entered the severe impact range of the working face $15 \mathrm{~m}$ ahead of the mining. When the main and auxiliary withdrawal spacing was $20 \mathrm{~m}$, the impact was predominantly severe.

\section{On-Site Monitoring and Effect Analysis}

The field mine pressure monitoring showed that the distance from the increasing mine pressure during the working face advancement was $25-40 \mathrm{~m}$. Therefore, we used FLAC to analyse the distribution characteristics of the maximum principal stress, minimum principal stress, and vertical stress within $0-50 \mathrm{~m}$ between the working face and the retreat passage. With the working face advancement, the stress between the front of the working face and the main retreat path changed from a bimodal asymmetrical distribution to a bimodal symmetrical distribution and eventually transformed into a unimodal distribution. In addition, the coal pillar size of the main and auxiliary withdrawal channels directly influenced the stability of the surrounding rock. A smaller coal pillar leads to a higher stress state of the coal body, unbeneficial to the surrounding rock stability. We found that the reasonable coal pillar size between the main and auxiliary withdrawal channels should be $25 \mathrm{~m}$. After the reasonable coal pillar size is determined, industrial field tests should be performed to validate the research conclusions.

4.1. Monitoring Plan. To verify the rationality of the coal pillar size, we marked monitoring points in the main and auxiliary withdrawal channels of the 31113 working face to observe the ore pressure. The main retraction channel was 


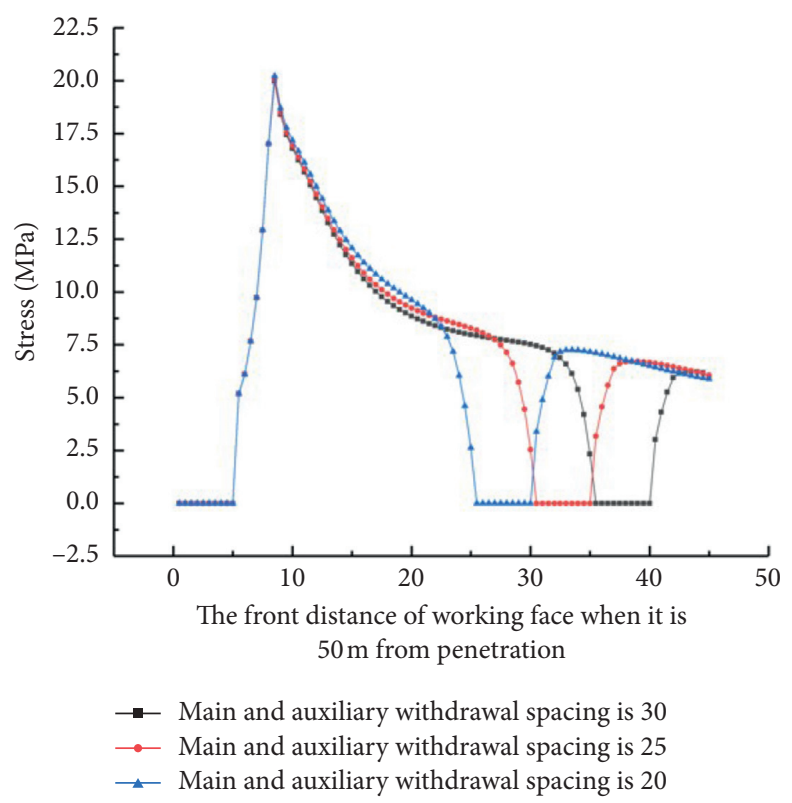

Figure 20: Vertical stress curve when Panel 31113 is penetrated.

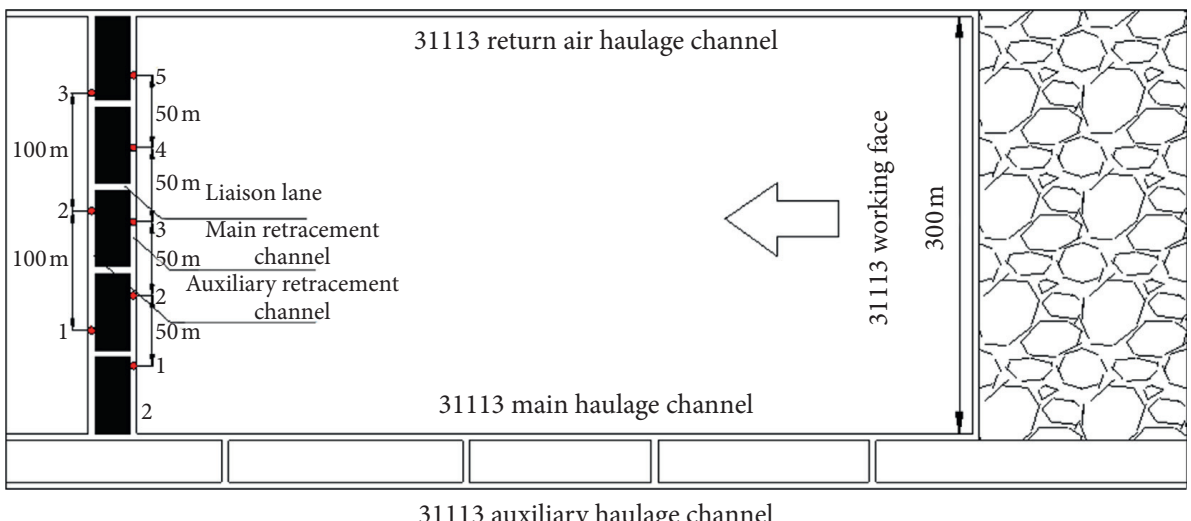

Figure 21: Schematic of the layout of surface displacement measurement points for withdrawal channel.

set with five measurement points, and the secondary retracement channel was set with three measurement points (Figure 21).

4.2. Monitoring Result Analysis. During the first observation, the working face was $45 \mathrm{~m}$ from the main recovery channel. Continuous mining pressure monitoring was then performed, the accumulated amount was adopted as the salt side amount, and the mining pressure behaviour of the surrounding rock was determined.

With the working face advancement in the final mining stage, the surrounding rock stress of the withdrawal channel changed significantly (Figures 22 and 23), leading to the deformation and failure of the surrounding rock. The deformations of the roof and floor of the main retreat passage were $20-45 \mathrm{~mm}$, and the rib deformation was $200-330 \mathrm{~mm}$. The rib near the working face was significantly larger. When the working face was $5 \mathrm{~m}$ from the main withdrawal channel, the coal body on the rib near the main withdrawal channel was completely damaged. This damage resulted in a significant convergence of the two ribs of the main withdrawal channel during the observation period.

During the final mining period, the two auxiliary withdrawal channels, roof and floor, did not undergo significant changes in displacement and were less affected by Panel 31113 mining with the working face advancement (Figures 24 and 25). The indents on the roof and floor ranged between 25 and $35 \mathrm{~mm}$, and the convergence of the two ribs ranged from 20 to $35 \mathrm{~mm}$.

Overall, with the continuous progression of the working face until the final working face was connected to the main withdrawal channel, the tunnel conditions were good. During the final mining period, the roadway was intact, except for the rib near the working face, and there was no roadway instability. The support was also in good working 


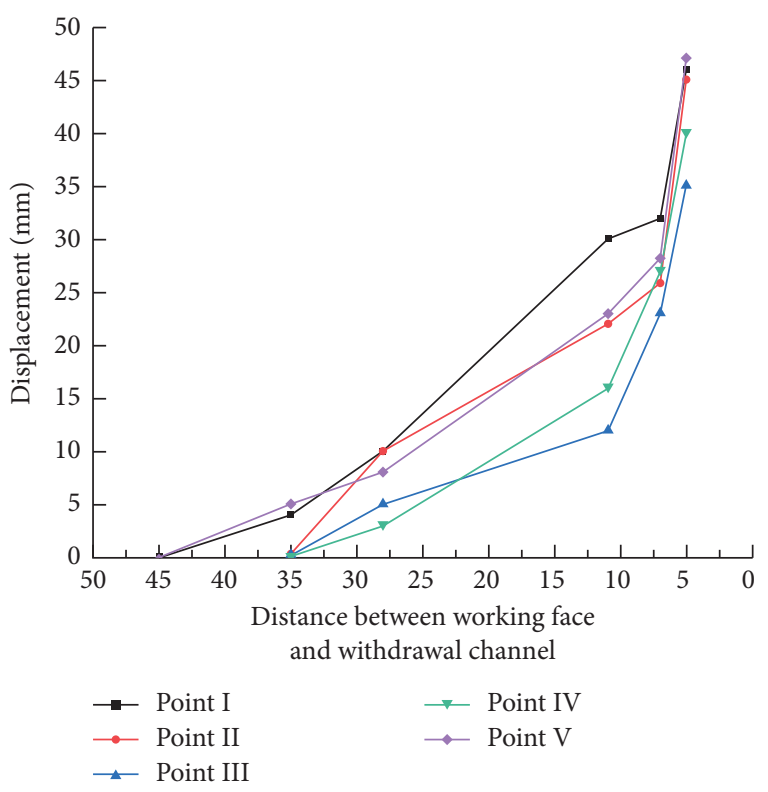

FIGURE 22: Roof and floor displacement of main withdrawal channel.

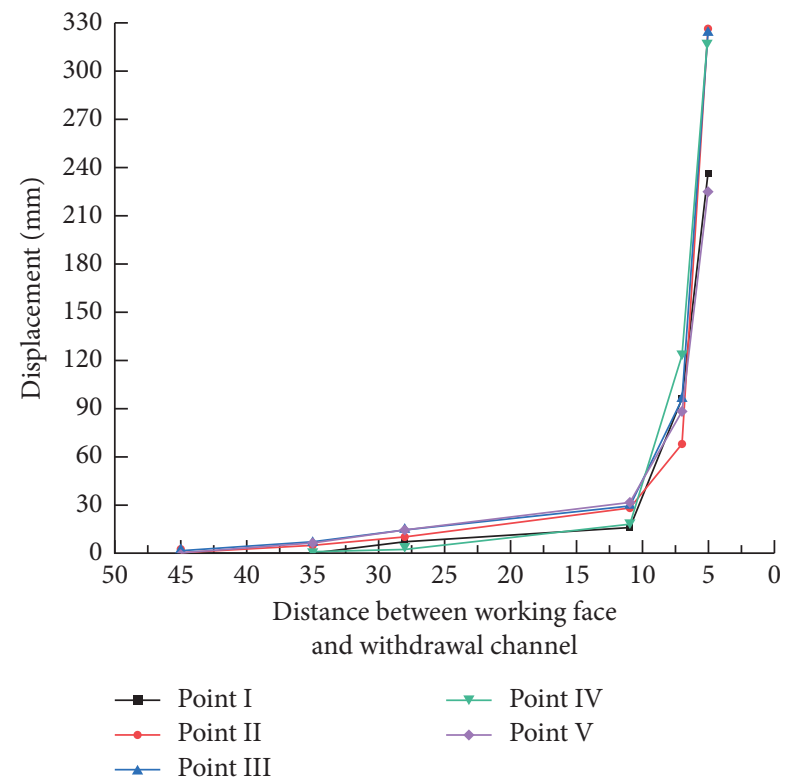

FIGURE 23: Displacement variations between ribs of main withdrawal channel.

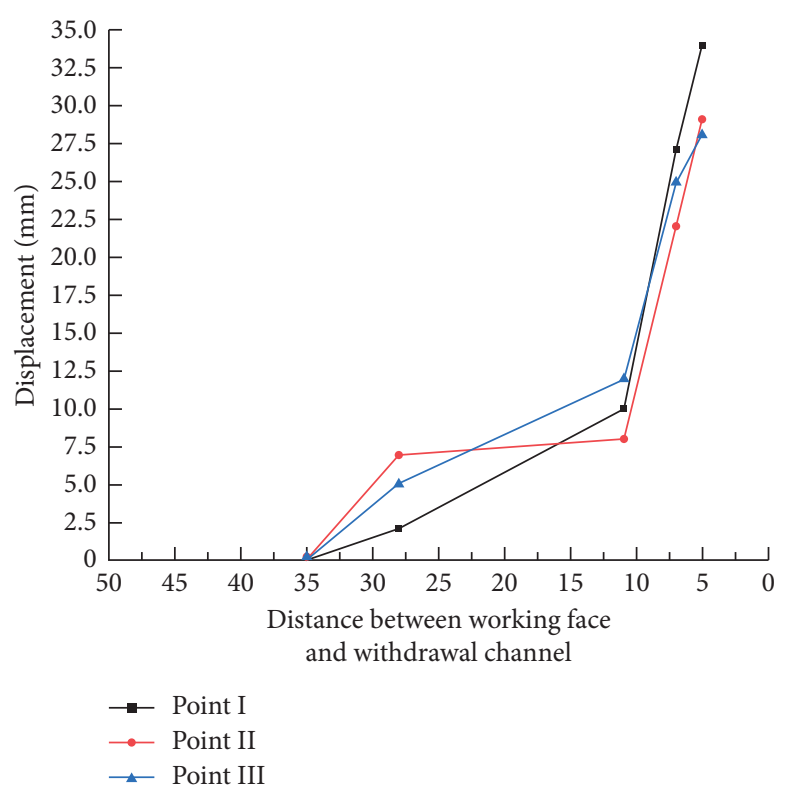

FIGURE 24: Roof and floor displacement variations in auxiliary withdrawal channel.

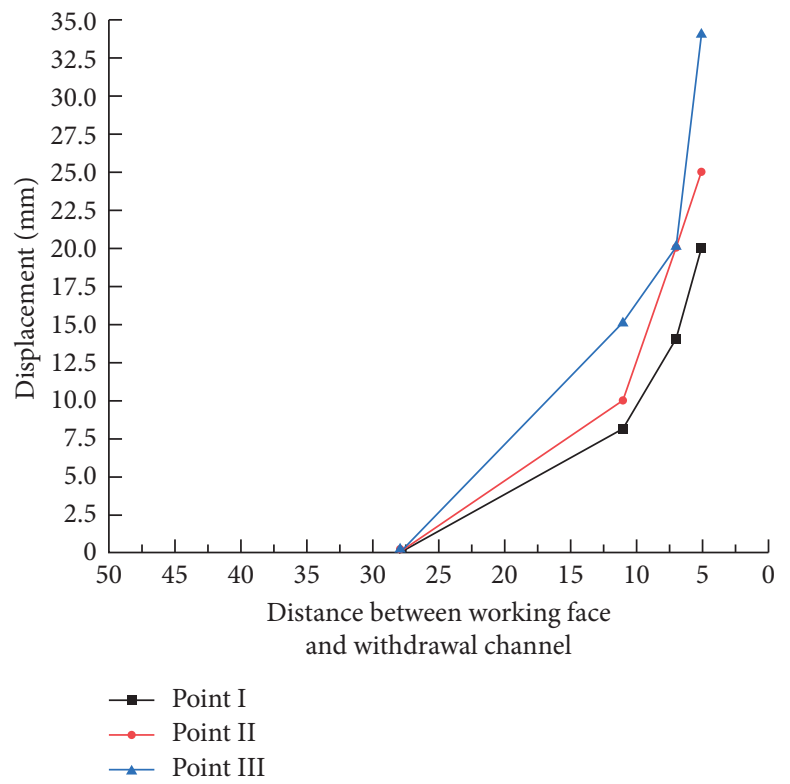

FIgURE 25: Displacement variations between ribs of auxiliary withdrawal channel. 
conditions, and the entire equipment withdrawal process was smooth.

\section{Conclusion}

In this study, the 31113 fully mechanised mining face of Lijiahao Coal Mine was selected as the engineering background. The failure characteristics of the surrounding rock and the reasonable spacing of the double-mining roadway were extensively investigated through theoretical analysis, field measurements, and numerical simulations. The main conclusions of this study are as follows:

(1) Through the surface displacement monitoring of the mining roadway at the 31113 working face, the influence of mining on the roadway was evaluated. The distance from the supporting pressure in the advance support in a fully mechanised mining face was 20-40 m.

(2) Using FLAC numerical simulation software, we determined the dynamic stress distribution characteristics. With the advancement of the working face, the stress between the front of the working face and the main retreat path changed from a bimodal asymmetrical distribution to a bimodal symmetrical distribution and finally transformed into a unimodal distribution. In addition, the coal pillar size of the main and auxiliary withdrawal channels directly influenced the stability of the surrounding rock. A smaller coal pillar results in a higher stress state in the coal body, which is unbeneficial to the surrounding rock stability. The obtained reasonable coal pillar size was $25 \mathrm{~m}$.

(3) Field tests on a reasonable coal pillar size were performed to observe the ore pressure behaviour of the withdrawal passage during the final mining period. The monitoring results indicated no large deformation or surrounding rock instability in the retreat passage, and the working face equipment could be withdrawn smoothly. The field tests verify the rationality of the proposed approach, and the study is a valuable reference for similar projects.

\section{Data Availability}

The data used to support the findings of this study are available from the corresponding author upon request.

\section{Conflicts of Interest}

The authors declare no conflicts of interest.

\section{Acknowledgments}

The authors wish to sincerely thank various organizations for their financial support. This work was partially supported by the National Natural Science Foundation of China (51234006).

\section{References}

[1] C. Li, X. F. Guo, X. Y. Lian, and N. J. Ma, "Failure analysis of a pre-excavation double equipment withdrawal channel and its control techniques," Energies, vol. 13, no. 23, pp. 1-17, 2020.

[2] M. G. Qian, P. W. Shi, and J. L. Xu, Mining Pressure and Strata Control, China University of Mining and Technology Press, Xuzhou, China, 2010.

[3] M. F. Cai, "Key theories and technologies for surrounding rock stability and ground control in deep mining," Journal of Mining and Strata Control Engineering, vol. 2, no. 3, pp. 5-13, 2020.

[4] C. Li, X. F. Guo, T. H. Huo, and R. Liu, "Coal pillar design of pre-excavated double equipment withdrawal channel and its surrounding rock stability control," Journal of Huazhong University of Science and Technology, vol. 49, no. 4, pp. 1-7, 2021.

[5] H. P. Kang, G. Xu, B. M. Wang et al., "Forty years development and prospects of underground coal mining and strata control technologies in China," Journal of Mining and Strata Control Engineering, vol. 1, no. 1, pp. 1-33, 2019.

[6] T. Cohen, R. Masri, and D. Durban, "Analysis of circular hole expansion with generalized yield criteria," International Journal of Solids and Structures, vol. 46, no. 20, pp. 3643-3650, 2009.

[7] L. Shi, H. D. Zhang, and P. Wang, "Research on key technologies of floor heave control in soft rock roadway," $A d$ vances in Civil Engineering, vol. 2020, Article ID 8857873, 13 pages, 2020.

[8] H. Yan, F. L. He, and S. G. Wang, "Safety control and evaluation of roadway with super-large cross-section and softweak thick coal roof," Chinese Journal of Rock Mechanics and Engineering, vol. 33, no. 5, pp. 1014-1023, 2014.

[9] P. K. Kaiser, S. Yazici, and S. Maloney, "Mining-induced stress change and consequences of stress path on excavation stability-a case study," International Journal of Rock Mechanics and Mining Sciences, vol. 38, no. 2, pp. 167-180, 2001.

[10] X. F. Guo, Z. Q. Zhao, X. Gao, Z. K. Ma, and N. J. Ma, "Directional sharp-point failure mechanism of rocks surrounding underground circular cavities subjected to largescale failure," Mathematical Problems in Engineering, vol. 2019, Article ID 1415387, 19 pages, 2019.

[11] X. F. Guo, Z. Q. Zhao, X. Gao, Z. K. Ma, and N. J. Ma, "The criteria of underground rock structure failure and its implication on rockburst in laneway a numerical method," Shock and Vibration, vol. 2019, Article ID 7509690, 12 pages, 2019.

[12] X. F. Guo, Z. Q. Zhao, X. Gao, X. Y. Wu, and N. J. Ma, "Analytical solutions for characteristic radii of circular roadway surrounding rock plastic zone and their application," International Journal of Mining Science and Technology, vol. 29, no. 2, pp. 263-272, 2019.

[13] B. Ghabraie, G. Ren, X. Y. Zhang, and J. Smith, "Physical modelling of subsidence from sequential extraction of partially overlapping longwall panels and study of substrata movement characteristics," International Journal of Coal Geology, vol. 140, no. 15, pp. 71-83, 2015.

[14] X. Wang, W. Yuan, Y. T. Yan, and X. Zhang, "Scale effect of mechanical properties of jointed rock mass: a numerical study based on particle flow code," Geomechanics and Engineering, vol. 21, no. 3, pp. 259-268, 2020.

[15] C. Jia and C. C. Hu, "Instability mechanism and control technology of longwall entries driving along the gob in a thick coal seam," Journal of Mining and Strata Control Engineering, vol. 2, no. 4, pp. 38-45, 2020. 
[16] H. Z. Yang, Z. Guo, D. Chen, C. Wang, F. Zhang, and Z. Du, "Study on reasonable roadway position of working face under strip coal pillar in rock burst mine," Shock and Vibration, vol. 2020, Article ID 8832791, 21 pages, 2020.

[17] R. R. Osgoui and E. Unal, "An empirical method for design of grouted bolts in rock tunnels based on the geological strength index (GSI)," Geotechnical \& Geological Engineering, vol. 107, no. 9, pp. 154-166, 2009.

[18] W. T. Li, Q. Wang, S. C. Li, and D. C. Wang, "Deformation and failure mechanism analysis and control of deep roadway with intercalated coal seam in roof," Journal of China Coal Society, vol. 39, no. 1, pp. 47-56, 2014.

[19] C. Li, Z. Wu, W. L. Zhang, Y. H. Sun, C. Zhu, and X. H. Zhang, "A case study on asymmetric deformation mechanism of the reserved roadway under mining influences and its control techniques," Geomechanics and Engineering, vol. 22, no. 5, pp. 449-460, 2020.

[20] W. L. Zhang, N. Ma, J. Ma, C. Li, and J. Ren, "Mechanism of rock burst revealed by numerical simulation and energy calculation," Shock and Vibration, vol. 2020, Article ID 8862849, 15 pages, 2020.

[21] X. J. Liu, S. L. Song, D. Y. Fan, and W. C. Fan, "Experimental study on deformation and failure evolution of surrounding rock for deep super-large section chamber group," Journal of Mining and Safety Engineering, vol. 37, no. 1, pp. 40-49, 2020.

[22] X. F. Wang, M. Y. Lu, Y. H. Gao, W. B. Luo, and W. G. Liu, "Structural mechanical characteristics and instability law of roof key block breaking in gob-side roadway," Advances in Civil Engineering, vol. 2020, Article ID 6682303, 12 pages, 2020.

[23] Y. Y. Wang, Y. Liu, C. Wang, L. C. Han, and G. H. Leng, "Optimizationand application research of soft rock roadway support scheme based on AHP," Journal of Mining and Strata Control Engineering, vol. 2, no. 2, pp. 40-48, 2020.

[24] H. Y. Wang, X. Y. Fang, Y. C. Li, Z. Y. Zheng, and J. T. Shen, "Research and application of the underground fire detection technology based on multi-dimensional data fusion," Tunnelling and Underground Space Technology, vol. 109, Article ID 103753, 2021.

[25] M. Rezaei, M. F. Hossaini, and A. Majdi, "Development of a time-dependent energy model to calculate the mining-induced stress over gates and pillars," Journal of Rock Mechanics and Geotechnical Engineering, vol. 7, no. 3, pp. 306-317, 2015.

[26] F. Du, K. Wang, X. Zhang, C. Xin, L. Shu, and G. Wang, "Experimental study of coal-gas outburst: insights from coalrock structure, gas pressure and adsorptivity," Natural Resources Research, vol. 29, no. 4, pp. 2481-2493, 2020.

[27] H. Y. Wang, X. Y. Fang, F. Du et al., "Three-dimensional distribution and oxidation degree analysis of coal gangue dump fire area: a case study," The Science of the Total Environment, vol. 772, no. 3, Article ID 145606, 2021.

[28] H. P. Kang, "Spatial scale analysis on coalmining and strata control technologies," Journal of Mining and Strata Control Engineering, vol. 2, no. 2, pp. 5-30, 2020.

[29] F. Q. Gao, "Use of numerical modeling for analyzing rock mechanic problems in underground coal mine practices," Journal of Mining and Strata Control Engineering, vol. 1, no. 2, pp. 21-28, 2019.

[30] P. Liang and Y. T. Gao, "Numerical investigation on cracking behavior of granite with intersecting two-flaws: a flat-joint modeling method," Latin American Journal of Solids and Structures, vol. 17, no. 4, pp. 1-14, 2020. 